\title{
An Experimentally Aided Operational Virtual Prototyping to Obtain the Best Spindle Speed during Face Milling of Large-Size Structures
}

\author{
Krzysztof J. Kaliński (D), Marek A. Galewski *(D), Michał R. Mazur (D) and Natalia Stawicka-Morawska (D) \\ Faculty of Mechanical Engineering and Ship Technology, Gdansk University of Technology, \\ 80-233 Gdansk, Poland; krzysztof.kalinski@pg.edu.pl (K.J.K.); michal.mazur@pg.edu.pl (M.R.M.); \\ natalia.morawska@pg.edu.pl (N.S.-M.) \\ * Correspondence: marek.galewski@pg.edu.pl
}

check for updates

Citation: Kaliński, K.J.; Galewski, M.A.; Mazur, M.R.;

Stawicka-Morawska, N. An

Experimentally Aided Operational

Virtual Prototyping to Obtain the Best Spindle Speed during Face Milling of Large-Size Structures. Materials 2021, 14, 6562. https://doi.org/10.3390/ ma14216562

Academic Editors: Grzegorz Królczyk and A. Javier Sanchez-Herencia

Received: 10 September 2021

Accepted: 26 October 2021

Published: 1 November 2021

Publisher's Note: MDPI stays neutral with regard to jurisdictional claims in published maps and institutional affiliations.

Copyright: (c) 2021 by the authors. Licensee MDPI, Basel, Switzerland. This article is an open access article distributed under the terms and conditions of the Creative Commons Attribution (CC BY) license (https:/ / creativecommons.org/licenses/by/ $4.0 /)$.

\begin{abstract}
The paper presents an original method concerning the problem of vibration reduction in the general case while milling large-size and geometrically complex details with the use of an innovative approach to the selection of spindle speed. A computational model is obtained by applying the so-called operational approach to identify the parameters of the workpiece modal model. Thanks to the experimental modal analysis results, modal subsystem identification was performed and reliable process data for simulation studies were obtained. Next, simulations of the milling process, for successive values of the spindle speed, are repeated until the best vibration state of the workpiece is obtained. For this purpose, the root mean square values of the time plots of vibration displacements are examined. The effectiveness of the approach proposed for reducing vibrations in the process of face milling is verified on the basis of the results of appropriate experimental investigations. The economic profitability of the implementation of the operational technique in the production practice of enterprises dealing with mechanical processing is demonstrated as well.
\end{abstract}

Keywords: face milling; cutting process dynamics; vibration suppression; hybrid modeling; modal analysis; virtual prototyping

\section{Introduction}

According to Fei et al. [1], dynamic phenomena during milling operations of large-size structures are manifested primarily in the relative vibrations of the tool and the workpiece. Hao et al. noted [2] that they impose significant restrictions on the further increase in productivity and product quality. In order to increase machining efficiency, Płodzień et al. proposed a new method called high feed milling [3]. However, its use results in a significant increase in the cutting force components and, as a consequence, the vibration level and deterioration of the surface roughness. Under certain circumstances, the growing vibrations can lead to instability, and then to self-excited vibrations referred as chatter, which was emphasized, for example, by Quintana and Ciurana [4], Mane et al. [5], and López de Lacalle et al. [6]. Chatter greatly reduces processing efficiency, worsens the machined surface (Urbikain et al. [7]), and may even lead to the destruction of tools and workpieces (Nouari et al. [8]). Although the appearance of chatter vibrations worsens surface finish and tool life rapidly decreases or may result in its destruction, few references in the literature seek the relationship between the level of controlled vibrations and machining accuracy as well as the durability of the cutting edges, e.g., by Li et al. [9].

The problem of chatter vibration prevention has been addressed in various ways. For example, Quintana and Ciurana [4] presented the state of research of chatter in the machining process and classified the existing methods that ensure stable cutting conditions. Similarly, Munoa et al. [10] critically reviewed the evolution of the different chatter suppression techniques. Yue et al. [11] presented the survey of methods and Zhu et al. [12] 
illustrated the current state-of-the-art regarding the problems of chatter prediction and detection in milling processes. The study of chatter stability of special milling tools such as variable pitch and crest-cut cutters was presented by Tehranizadeh et al. [13]. Liu and Zhou [14] described the research overview of chatter stability during the milling of thin-walled parts. In particular, it applied to the milling of thin floors considered by Campa et al. [15] and Dang et al. [16]. Yang et al. [17] focused on the efficient decompositioncondensation method to predict chatter in the in-process workpiece dynamics when applied to thin-walled parts. Liu et al. [18] presented a position-oriented process monitoring model based on correlation of the cutting position with cutting force, acceleration, and spindle power to improve the machining quality and efficiency. In [19], Ren et al. obtained chatter stability by application of the semi discretization method based on the integrated vibration model and the cutting dynamics. In [20], Artetxe et al. presented a cutting force prediction model that included tool runout and workpiece flexibility. However, the effective use of the above proposed developments is facing serious obstacles because of the interference with the structure of the machine. The latter especially concerns a wide group of active damping methods, such as application of the optimal control for chatter mitigation in milling (Monnin et al. [21]), and the use of the own drives of a large milling machine to suppress chatter, together with an external accelerometer located close to the center point of the tool (Munoa et al. [22]). Feng et al. [23] considered the varying stiffness of the milling system. Wan et al. [24] analyzed damping of milling chatter vibration by means of a contactless electromagnetic actuator with two degrees of freedom integrated in the spindle system, while Moradi et al. [25] displayed suppression of regenerative chatter in nonlinear milling processes. The other group obeys semi-active methods, e.g., sliding mode control and an electromagnetic actuator for which the velocity state in a closed-loop control with feedback is not needed (Wan et al. [26]), usage of an electromagnetic spring with adjustable negative stiffness in semi-active control (Pu et al. [27]), or replacing the mass element with an inerter in a classic passive damper (Wang et al. [28]). Díaz-Tena et al. [29] applied magnetorheological fluids to reduce vibrations when milling thin floor elements in high-speed machining under conditions where there is instability at theoretically optimal cutting parameters. Muhammad et al. [30] reviewed the state-of-the-art on the control of machining chatter vibrations, including damping methods related to boring, turning, and milling processes. Besides, we observe usage of a magnetorheological damper device to modify the stability boundaries with a significant increase in the productivity factor of thin-floor components (Puma-Araujo et al. [31]), as well as vibration-assisted machining (Chen et al. [32]). In real applications, much more sophisticated techniques and algorithms for chatter detection can be used. Thus, Albertelli et al. [33] developed an algorithm to be implemented as real-time chatter detection in industrial conditions or even as a module of a vibration control system. Yao et al. [34] dealt with real-time chatter detection and automatic suppression as well, but concerning intelligent spindle systems. Yang et al. [35] disclosed that the approximate entropy and the sample entropy were applicable to continuous and intermittent chatter detection in milling. Caliskan et al. [36] presented an online chatter detection method by monitoring the increasing vibration energy of non-periodic components. Aside from being technologically advanced, they are often costly and thus have limited use in industrial conditions.

The methodology of vibration suppression through spindle speed variation in highspeed milling by slender tools was successfully applied by Song et al. [37] and Urbikain et al. [38]. The efficiency of the modified method of vibration suppression in the potentially unstable regions of spindle speeds, resulting from the position of stability lobes, was confirmed by Kaliński and Galewski [39]. Vibration suppression using the method of spindle speed variation, however, is less effective in the case of milling flexible structures. Thus, the further developments led to the minimization of the cutting forces work along the direction of the corresponding cutting layer thickness, as illustrated by Kaliński and Galewski [40], as well as by Kaliński [41]. Subsequently it should also be noted (Kaliński et al. [42]) that this method may not offer the possibility of operating within 
the full range of spindle speeds of the machine tool. Moreover, methods focusing solely on the reduction of chatter overlook other dynamic phenomena of more significant importance in the machining of large-size workpieces, e.g., forced vibrations, although, according to Uriarte et al. [43], the chatter vibration phenomenon cannot be treated as the only challenge for the development of vibration suppression methods.

The above proves that only simulations of the computational model of the large-size machining process, taking into account the complex state of vibrations at the same time, are a reasonable means leading to an effective solution. Examples of simulation techniques used so far include the following:

- Virtual time simulation i.e., virtual prototyping (VP). During the simulation, a simplified model of the tool (all cutting teeth are exactly the same) and the workpiece is assumed, and some effects (appearing in the experiment) are ignored (for example, the effects of balancing and tool bending considered by Totis et al. [44]). In order to improve the validity of the calculation model, Kaliński et al. [45] proposed a technique of the experimentally aided virtual prototyping (EAVP);

- Hardware in the loop simulation (HiLS) used by Kaliński and Galewski [46] to emulate at least a part of a controlled mechanical structure or process, and the rest remained a material structure. The HiLS technique allows us to speed up the process of creating a control system and software;

- Hardware simulation of the dynamics of the milling process, used by Yao et al. [47], Fu et al. [48], and Kuljanic et al. [49] to develop a device that detects chatter vibrations. An appropriate model of the workpiece, tool, and cutting process should be derived. Then, proper programming and optimization techniques must be applied to fulfill real-time (RT) constraints. Moreover, hardware solutions, especially based on field programmable gate array (FPGA), may be required to achieve a better response time and better system reliability and repeatability (Mazur et al. [50], RodríguezAndina et al. [51]). In some solutions, e.g., developed by Fayose [52], mechanical systems are simulated with the use of analog electronics;

- The combination of software programming techniques with reconfigurable input/output architecture and real-time FPGA capabilities, proposed by Urbikain et al. [53]. A personal application specifically geared towards machining simulation allows you to simultaneously record the following: machining forces, accelerations, noise, and/or sound pressure. The LabVIEW FPGA module has compiled the LabVIEW VI to the FPGA hardware;

- The combination of HiLS techniques with the advantages of real-time FPGA simulation, enabling the construction of an HiLS system and taking into account very tight time constraints, as suggested by Naets et al. [54]. FPGA-based RT systems have very short response times and low jitter values that can be limited to a few nanoseconds.

As there is no explicit control signal in the expected milling simulation process of large-size workpieces, thanks to which there is no need to operate in the real-time domain, the technique of experimentally aided operational virtual prototyping (EAOVP) was used in the newly presented method. It was developed as a result of a creative and significant modification of the EAVP technique, previously elaborated by Kaliński et al. [45]. The main differences and advantages of the introduced modifications, compared with the existing technique, are as follows:

- Elimination of the labor-intensive and time-consuming stage of assessing the compliance of the finite element model (FEM) with the real object, because this stage greatly extends the process of creating a computational model, which is then subjected to simulation;

- Simplification of the previously adopted computational model of a rigid milling tool, in accordance with the convention of the rigid finite element method (RFEM), briefly and synthetically described by Kaliński [41], and taking into account the dynamics of the workpiece changing over time; 
- Simultaneously ensuring the cost-effectiveness of the proposed approach without losing the required machining accuracy.

\section{Simulation Model}

\subsection{Cutting Process Dynamics}

The subject of the considerations is the process of face milling of a flexible workpiece with a multi-edge milling cutter. The dynamics of the machining process was analyzed with the following assumptions (Kaliński [41], Kaliński et al. [45]):

- The tool fixed in the holder, rotating with the desired spindle speed $n$, and the workpiece mounted on the table, moving with the desired feed speed $v_{f}$, are the only ones taken into account. The influence of the remaining parts of the milling machine on the dynamics of the machining process can be neglected (Fei et al. [1], Uriarte et al. [43]).

- The flexibility of the workpiece, which characterizes the machining of large-size flexible elements on multi-axis machining centers, was taken into account (Fei et al. [1], Kaliński et al. [45]).

- $\quad$ For modeling the dynamics of the cutting process, coupling elements (CEs) were adopted, which were located at the conventional contact points of the tool edges with the workpiece (Kaliński [41]). The momentary positions of the tips of the cooperating edges of the rotating tool were assumed as these points.

- The passage of the current edge along the cutting layer causes a proportional feedback, and the passage of the previous edge additionally causes a delayed feedback. Thanks to this, it is possible to consider the effect of multiple trace regeneration in the calculation model.

As a result of modeling the dynamics of the milling process, a system was obtained (Figure 1) consisting of the following: a rigid body called the rigid finite element (RFE), connected to a support (tool holder) by means of the spring damping element (SDE) (Kaliński [41]); a stationary model mapping the structure of a flexible workpiece; and coupling elements (CEs), the positions of which correspond to the instantaneous positions of the tool edges tips and change with respect to time (Kaliński [41]). The momentary position of the cutter edge no. $l$ is described by the immersion angle $\phi_{l}=\phi_{l}(t)$. It corresponds to the temporary position of $\mathrm{CE}$ no. $l$, and the axes $y_{l 1}, y_{l 2}$, and $y_{l 3}$ are the coupling axes of this CE (Kaliński [41]). During the machining process, not all edges are cutting the material at any given time. The cutting edges were labelled "active".

Moreover, the scheme of the milling process shows the following:

- Rake angle $\gamma_{0}$ and clearance angle $\alpha_{0}$, as elements of edge geometry in the orthogonal plane;

- Cutting edge angle $\kappa_{r}$;

- Force $F_{y l 1}$, acting in the direction of the nominal cutting speed $v_{c}$;

- The current thickness of the cutting layer $h_{l}$ and the force acting in its direction $-F_{y l 2}$;

- The current width of the cutting layer $b_{l}$ and the force acting in its direction $-F_{y l 3}$;

- Depth of cutting $a_{p}$;

- $\quad$ Milling diameter $D$;

- Milling widths $B_{1}$ and $B_{2}$; for full milling, $B_{1}=B_{2}$; down milling, $B_{1}<B_{2}$; and up milling, $B_{1}>B_{2}$;

- Local coordinate system $x_{r 1}, x_{r 2}$, and $x_{r 3}$ of the RFE;

- Conventional point $S$ of the contact of the tool with the workpiece (Kaliński [41], Kaliński et al. [45]) and the non-rotating coordinate system $x_{1}, x_{2}$, and $x_{3}$ for this point, but moving linearly with respect to the workpiece. 


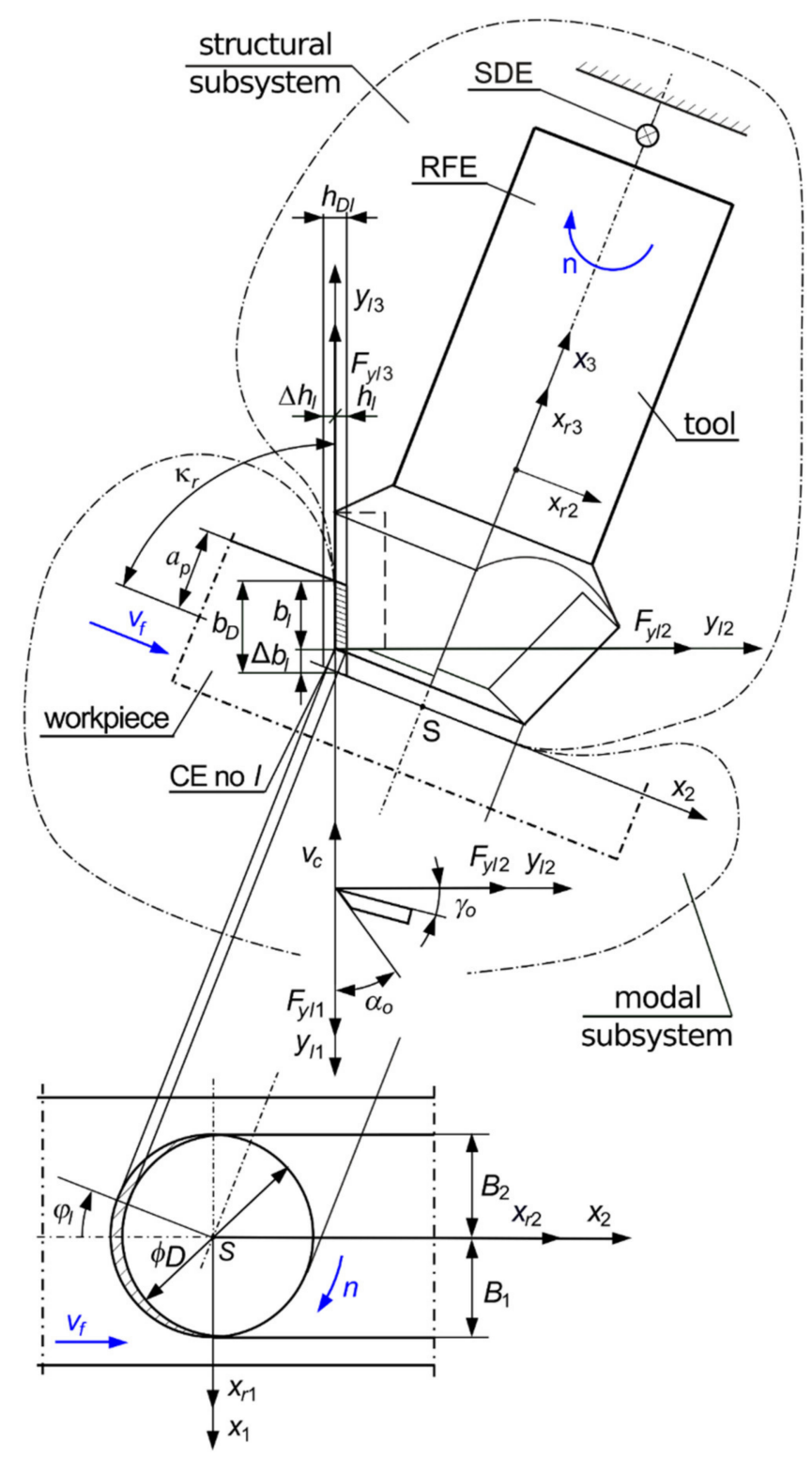

Figure 1. Scheme of a face milling of a flexible workpiece.

An important goal is to formulate a model of the influence of the changing contact zone of the cutting tool with the workpiece on the dynamic characteristics of the cutting process. Thus, the characteristics "cutting force-zone geometry-cutting velocity" require both theoretical and experimental investigations in the case of intermittent cutting (Ehmann et al. [55], Lee et al. [56]). The above is faced with a number of obstacles, caused by the following:

- Various operating regimes, that is to say, pure ploughing, simultaneous ploughing, and shearing, and shearing may govern the cutting process. Based on linearized cutting dynamics models characterizing these regimes, a generalized approach to dealing with nonlinear force effects is being proposed by Yoon and Ehmann [57];

- $\quad$ The need to determine the constitutive relationship of the processed material. The purpose of the research is to determine the characteristics between normal stress, plastic deformation, deformation rate, and temperature, for various cut materials. Within a range of elasticity, the mechanical properties of the material (i.e., Young modulus and Poisson's ratio) are well described. Within a range of plasticity, the appropriate relationship becomes more complicated, and thus requires experimental investigation (Kpenyigba et al. [58]); 
- The need to evidence the hypothesis about the flexible workpiece plasticity existence in the contact zone of edge and workpiece, and its influence on the cutting process dynamic characteristics (Faure et.al. [59]). New cutting force characteristics can be applied for further application in the simulation model;

- $\quad$ The need to verify cutting force characteristics of the intermittent cutting process dynamics, considering in the calculation model the workpiece nonlinearity in a range of plastic deformations (Castro et al. [60]).

Owing to the above difficulties, the mechanistic modeling of the cutting force is applied to numerically estimate the components of the cutting force (Fei et al. [1], Kiran and Kayacan [61]), which seems to be a more convenient attempt. For the temporary point of contact of the tool edge with the workpiece, modeled as CE no. $l$, a proportional model of the dynamics of the cutting process was adopted (Kalinski and Galewski [40], Kaliński [41]), which also takes into account the effects of internal and external modulation of the layer thickness and the edge exit from the workpiece. This approach is justified by significant (above $100 \mathrm{~m} / \mathrm{min}$ ) cutting speed values (Kaliński [41]). According to the assumptions of the adopted model of the cutting process, and taking into account the changes in the thickness $h_{l}(t)$ and width $b_{l}(t)$ of the cutting layer over time, the components of cutting forces were obtained in the following form (Kalinski et al. [45]):

$$
\begin{gathered}
F_{y l 1}(t)= \begin{cases}k_{d l} b_{l}(t) h_{l}(t), & h_{l}(t)>0 \wedge b_{l}(t)>0, \\
0, & h_{l}(t) \leq 0 \vee b_{l}(t) \leq 0,\end{cases} \\
F_{y l 2}(t)= \begin{cases}\mu_{l 2} k_{d l} b_{l}(t) h_{l}(t), & h_{l}(t)>0 \wedge b_{l}(t)>0, \\
0, & h_{l}(t) \leq 0 \vee b_{l}(t) \leq 0,\end{cases} \\
F_{y l 3}(t)= \begin{cases}\mu_{l 3} k_{d l} b_{l}(t) h_{l}(t), & h_{l}(t)>0 \wedge b_{l}(t)>0, \\
0, & h_{l}(t) \leq 0 \vee b_{l}(t) \leq 0,\end{cases}
\end{gathered}
$$

where

$b_{l}(t)=b_{D}-\Delta b_{l}(t)$,

$h_{l}(t)=h_{D l}(t)-\Delta h_{l}(t)+\Delta h_{l}\left(t-\tau_{l}\right)$,

$b_{D}$-desired cutting layer width; $b_{D}=a_{p} / \sin \kappa_{r}$ (Mazur et al. [50]);

$\Delta b_{l}(t)$ - dynamic change in cutting layer width for CE no. $l$;

$h_{D l}(t)$ —desired cutting layer thickness for CE no. $l ; h_{D l}(t) \cong f_{z} \sin \kappa_{r} \cos \phi_{l}(t)$ (Mazur et al. [50]);

$\Delta h_{l}($.$) -dynamic change in cutting layer thickness for CE no. l$;

$k_{d l}$-average dynamic specific cutting pressure for CE no. $l$;

$\mu_{l 2}, \mu_{l 3}$ - cutting force ratios for CE no. $l$, as quotients of forces $F_{y l 2}$ and $F_{y l 1}$, and forces $F_{y l 3}$ and $F_{y l 1}$;

$\tau_{l}$ - time-delay between the same position of CE no. $l$ and of CE no. $l-1$;

$\kappa_{r}$ - cutting edge angle;

$f_{z}$-feed per tooth; $f_{z}=v_{f} /(n z)$;

$z$-number of milling cutter teeth.

It is worth noting that, in order to explicitly define these forces, it is necessary and sufficient to know only three parameters, $k_{d l}, \mu_{l 2}$, and $\mu_{l 3}$ of abstractive significance, the numerical values of which can be adjusted by comparing the respective root mean square (RMS) values of the computational model and the milling process being carried out (see Section 3).

The description of cutting forces for CE no. $l$ in six-dimensional space is disclosed and takes the following form (Kaliński et al. [45], Mazur et al. [50]):

$$
\mathbf{F}_{l}(t)=\mathbf{F}_{l}^{0}(t)-\mathbf{D}_{P l}(t) \Delta \mathbf{w}_{l}(t)+\mathbf{D}_{O l}(t) \Delta \mathbf{w}_{l}\left(t-\tau_{l}\right)
$$


where

$$
\begin{aligned}
& \mathbf{F}_{l}(t)=\operatorname{col}\left(F_{y l 1}(t), F_{y l 2}(t), F_{y l 3}(t), 0,0,0\right), \\
& \mathbf{F}_{l}^{0}(t)=\operatorname{col}\left(k_{d l} b_{D} h_{D l}(t), \mu_{l 2} k_{d l} b_{D} h_{D l}(t), \mu_{l 3} k_{d l} b_{D} h_{D l}(t), 0,0,0\right), \\
& \mathbf{D}_{P l}(t)=\left[\begin{array}{cccc}
0 & k_{d l}\left(b_{D}-\Delta b_{l}(t)\right) & k_{d l} h_{D l}(t) & \\
0 & \mu_{l 2} k_{d l}\left(b_{D}-\Delta b_{l}(t)\right) & \mu_{l 2} k_{d l} h_{D l}(t) & \mathbf{0}_{3 \times 3} \\
0 & \mu_{l 3} k_{d l}\left(b_{D}-\Delta b_{l}(t)\right) & \mu_{l 3} k_{d l} h_{D l}(t) & \\
& \mathbf{0}_{3 \times 3} & & \mathbf{0}_{3 \times 3}
\end{array}\right], \\
& \mathbf{D}_{\mathrm{Ol}}(t)=\left[\begin{array}{cccc}
0 & k_{d l}\left(b_{D}-\Delta b_{l}(t)\right) & 0 & \\
0 & \mu_{l 2} k_{d l}\left(b_{D}-\Delta b_{l}(t)\right) & 0 & \mathbf{0}_{3 \times 3} \\
0 & \mu_{l 3} k_{d l}\left(b_{D}-\Delta b_{l}(t)\right) & 0 & \\
& \mathbf{0}_{3 \times 3} & & \mathbf{0}_{3 \times 3}
\end{array}\right] \text {, } \\
& \Delta \mathbf{w}_{l}(t)=\operatorname{col}\left(q_{z l}(t), \Delta h_{l}(t), \Delta b_{l}(t), 0,0,0\right), \\
& \Delta \mathbf{w}_{l}\left(t-\tau_{l}\right)=\operatorname{col}\left(q_{z l}\left(t-\tau_{l}\right), \Delta h_{l}\left(t-\tau_{l}\right), \Delta b_{l}\left(t-\tau_{l}\right), 0,0,0\right),
\end{aligned}
$$

where $q_{z l}(t)$-relative displacement of edge tip and workpiece along direction $y_{l 1}$ at instant of time $t$ and $q_{z l}\left(t-\tau_{l}\right)$-relative displacement of edge tip and workpiece along direction $y_{l 1}$ at instant of time $t-\tau_{l}$.

The illustrated considerations take into account all the most important non-linear effects observed in real milling operations, that is to say (Kaliński et al. [45]):

- The loss of contact between the cutting tool edge and the workpiece, owing to the lower limitation of the cutting force characteristics (1)-(3);

- The geometric non-linearity resulting from the dependence on the dynamic change in the width of the cutting layer (see Equations (7) and (8)).

As a result of modeling the dynamics of the milling process, a hybrid system is obtained, which consists of the following (Figure 1):

- A modal subsystem, i.e., a stationary model of a flexible workpiece moving with a given feed speed $v_{f}$. Its behavior is described by the vector of its modal coordinates a. No FEM is included, and the parameters of the modal model, unlike in Kaliński et al. [45], are obtained only from the experiment. Therefore, taking into account the finite number of normal modes mod of the subsystem, we define its dynamic properties with the following:

$\mathbf{\Omega}=\operatorname{diag}\left(\omega_{0 i}\right)-$ matrix of angular natural frequencies of the modal subsystem; $i=1$, ..., mod; its square is also called the stiffness modal matrix;

$\mathbf{\Psi}=\left[\begin{array}{lll}\mathbf{\Psi}_{1} & \ldots & \mathbf{\Psi}_{\text {mod }}\end{array}\right]$ 一 matrix of the considered mass-normalized normal modes of the modal subsystem; $i=1, \ldots, \bmod$;

$\mathbf{Z}=\operatorname{diag}\left(\zeta_{i}\right)$-matrix of dimensionless damping coefficients (also called modal damping) of the modal subsystem; $i=1, \ldots$, mod.

Another important argument for the desirability of description in modal coordinates is that the physical properties of the workpiece do not change with time. In the case of processing objects of large dimensions, we deal with a small (approximately 1 per mille) allowance for material removal in relation to the total mass of the object;

- A structural subsystem, i.e., a discrete model (the RFE and the SDE) of a rotating milling cutter with a given spindle speed $n$. The behavior of the subsystem is described by the vector of its generalized coordinates q. The small number (i.e., 6) of these coordinates, additionally having an unambiguous physical interpretation, does not justify the desirability of describing the behavior of the dynamics of the rotating tool in modal coordinates (Eksioglu et al. [62]). The dynamic properties of the structural subsystem are defined by inertia $\mathbf{M}$, damping $\mathbf{L}$, and stiffness $\mathbf{K}$ matrices. The way of determining these matrices is shown in the Appendix A;

- An abstractive connecting subsystem such as, unlike in Kaliński et al. [45], a set of conventional points of contact of the tool edges with the workpiece. Their generalized 
coordinates are related to other coordinates through time-dependent constraint equations (Kaliński [41]). This allows to eliminate these generalized coordinates from the description of the behavior of the hybrid system.

\subsection{Dynamics of the Milling Process of Flexible Workpieces in Hybrid Coordinates}

Let us describe the dynamics of the non-stationary hybrid model of the milling process in hybrid coordinates. Then, the matrix equation of the dynamics will take the following form (Kaliński [41], Kaliński et al. [45]):

$$
\begin{gathered}
{\left[\begin{array}{cc}
\mathbf{M} & \mathbf{0} \\
\mathbf{0} & \mathbf{I}
\end{array}\right] \ddot{\boldsymbol{\xi}}+\left[\begin{array}{cc}
\mathbf{L} & \mathbf{0} \\
\mathbf{0} & 2 \mathbf{Z} \boldsymbol{\Omega}
\end{array}\right] \dot{\boldsymbol{\xi}}+\left[\begin{array}{cc}
\mathbf{K}+\sum_{l=1}^{i_{l}} \mathbf{T}_{l}^{T}(t) \mathbf{D}_{P l}(t) \mathbf{T}_{l}(t) & -\sum_{l=1}^{i_{l}} \mathbf{T}_{l}^{T}(t) \mathbf{D}_{P l}(t) \mathbf{W}_{l}(t) \\
-\sum_{l=1}^{i_{l}} \mathbf{W}_{l}^{T}(t) \mathbf{D}_{P l}(t) \mathbf{T}_{l}(t) & \mathbf{\Omega}^{2}+\sum_{l=1}^{i_{l}} \mathbf{W}_{l}^{T}(t) \mathbf{D}_{P l}(t) \mathbf{W}_{l}(t)
\end{array}\right] \xi=} \\
=\left[\begin{array}{c}
\sum_{l=1}^{i_{l}} \mathbf{T}_{l}^{T}(t) \mathbf{F}_{l}^{0}(t)+\mathbf{T}_{l}^{T}(t) \mathbf{D}_{O l}(t) \Delta \mathbf{w}\left(t-\tau_{l}\right) \\
-\sum_{l=1}^{i_{l}} \mathbf{W}_{l}^{T}(t) \mathbf{F}_{l}^{0}(t)-\mathbf{W}_{l}^{T}(t) \mathbf{D}_{O l}(t) \Delta \mathbf{w}\left(t-\tau_{l}\right)
\end{array}\right]
\end{gathered}
$$

where

$\xi=\left\{\begin{array}{l}\mathbf{q} \\ \mathbf{a}\end{array}\right\}$-vector of hybrid coordinates of the hybrid system;

$\mathbf{T}_{l}(t)$-transformation matrix of displacements' vector $\mathbf{q}$ from the $x_{r 1}, x_{r 2}$, and $x_{r 3}$ coordinates of the RFE, to the coordinate system $y_{l 1}, y_{l 2}$, and $y_{l 3}$ of CE no. $l$ (Kaliński [41]) (see the Appendix A);

$\mathbf{W}_{l}(t)$-transformation matrix between the displacement vector in modal coordinates a, and displacements in the coordinate system $y_{l 1}, y_{l 2}$, and $y_{l 3}$ of CE no. $l$ (Kaliński [41]);

$i_{l}$-number of "active" CEs.

The structural subsystem and the modal subsystem remain stationary before the connection. Only after they are combined into a hybrid model does the entire system become non-stationary, owing to the apparent variability in time resulting from the given movements of the subsystems. Time domain simulations based on Equation (11) take into account the change in the geometric positions of the instantaneous contacts of the tool edges with the workpiece.

In order to identify the modal model of the flexible workpiece (being part of Equation (11)), the matrix of normal modes $\boldsymbol{\Psi}$, the matrix of dimensionless damping coefficients $\mathbf{Z}$, and the matrix of corresponding angular natural frequencies $\Omega$ of the modal subsystem should be determined. Thanks to separation of the modal subsystem from the entire nonstationary structure, a significant reduction in the size of the model to only a few modes is obtained. The number of modes depends on their importance and the need for selecting modes for further analysis.

Normal modes remain unchanged over time owing to the immobility of the modal subsystem during the machining process. Thanks to this, only the normal modes $\Psi$, dimensionless damping coefficients $\mathbf{Z}$, and angular frequencies $\Omega$ can be identified, unlike in [45], by the methods of experimental modal analysis (EMA) on the workpiece installed on the milling machine table.

In various zones of the milled surface, different dominant vibration modes can be observed, especially in the case of large workpieces or workpieces with complicated geometrical shapes. Therefore, in the case of the modal model obtained directly from the experiment, it is assumed that the dominant modes are those identified on the basis of the frequency response function (FRF), measured only at points lying on the machined surface.

\section{Experimentally Aided Operational Virtual Prototyping}

In Kaliński et al. [45], the technique of experimentally aided virtual prototyping (EAVP), based on the validated modal approach, was elaborated. As a result of progressive 
modifications introduced in this method, a new technique of experimentally aided operational virtual prototyping (EAOVP) was proposed, based solely on the experimental modal model of the workpiece, linear interpolation of the identified modes, and simulation of the milling process performance. The latter resulted in the following spindle speed selection procedure (Figure 2):

1. Estimation of modal parameters using only EMA. The latter concerns natural frequencies $f_{\beta}^{e}$, modal damping coefficients $\zeta_{\beta}^{e}$, and normal modes $\Psi_{\beta}^{e},=1, \ldots, \bmod$. Only excitation and response measurement points lying on the machined surfaces are taken into consideration.

2. Linear interpolation of the identified modes along the toolpath on the workpiece surface modelled in the simplified manner.

3. Dominant modes are selected in order to be used in the modal subsystem of the hybrid model of the milling process.

4. Determination of simulation parameters $\left(k_{d l}, \mu_{l 2}, \mu_{l 3}\right)$ of the cutting process, adjusting the results of milling simulations carried out for the nominal (standard) spindle speed to the results of the real cutting performed for the same spindle speed.

5. Milling process simulations for various spindle speeds in the selected range. Cutting process parameters specified in p. 4 are applied.

6. For a set of simulated milling processes, vibration levels are observed, i.e., the root mean square (RMS) of relative tool-workpiece displacements; based on these results, the best spindle speed is selected.

7. Performance of the real milling process with the selected best spindle speed.

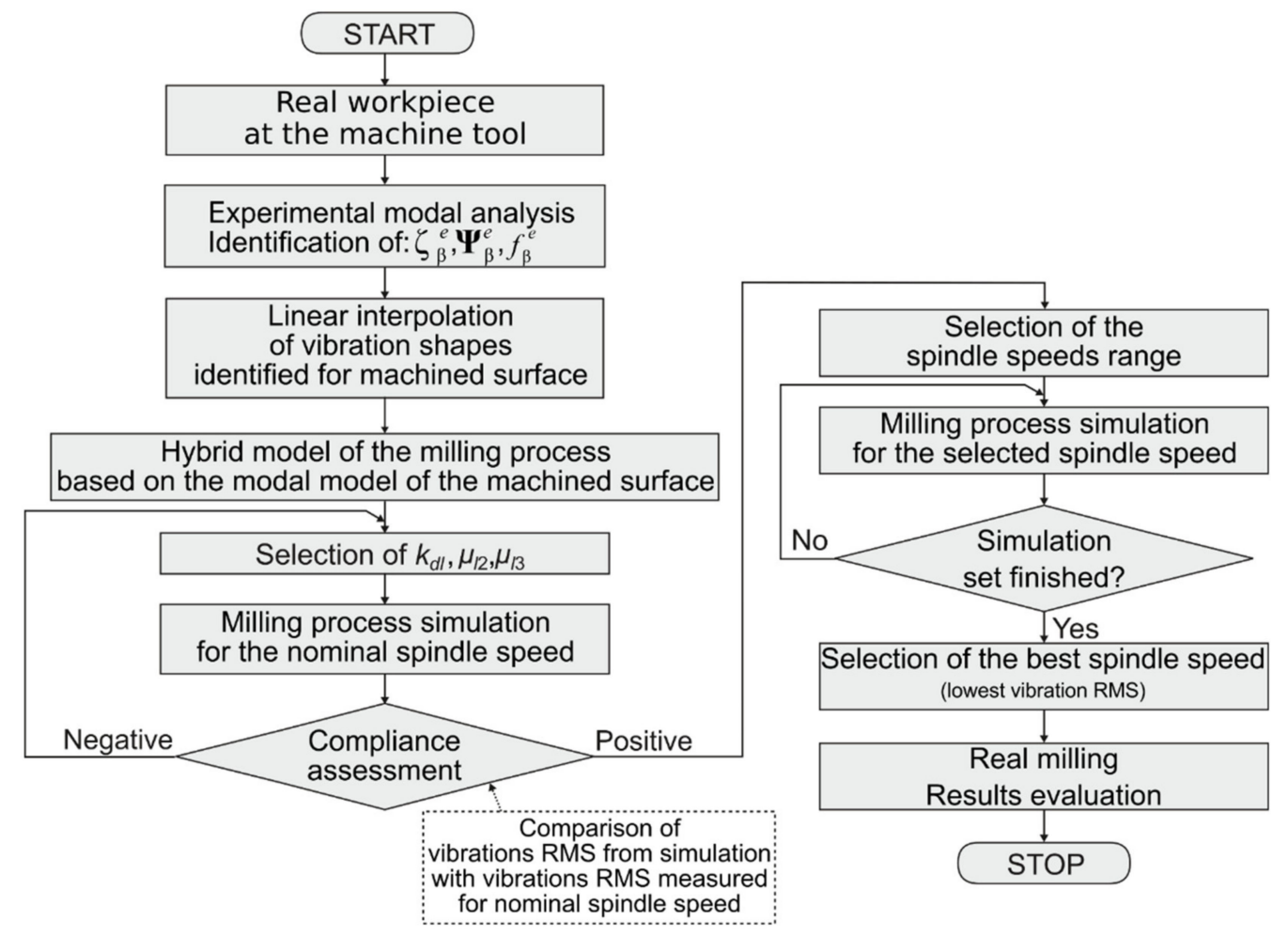

Figure 2. Scheme of the EAOVP on the basis of linear interpolation.

The advantage of the proposed method over the EAVP (Kaliński et al. [45]) is as follows:

- The precise obtaining of the best value of the spindle speed requires a much shorter time. After all, the calculation model of the workpiece is simplified only to the milling area model. There is no need to prepare a complex finite element model (FEM) of the whole workpiece and to correlate it according to the modal test, which is a very time-consuming task; 
- Only modes that are important from the point of view of modelling the behavior of the machined surface are considered;

- Dominant frequencies and modal damping coefficients are identified directly from modal tests, and thus they are more accurate;

- Selection of dominant modes is natural as only important modes are observed when the workpiece excitation is applied on the machined surface. Because of this, the number of normal modes is usually lower than in the case of the previous technique of EAVP (Kaliński et al. [45]).

The presented algorithm (Figure 2) does not require the purchase of expensive commercial FEM software, as well as the involvement of expensive and complex systems of measurement and control equipment. The proprietary linear interpolation procedures and simulation of the hybrid model of the milling process were launched with the use of free programming environments. Hence, the algorithm in the disclosed version can easily be directly implemented in an engineering practice where the "real milling" schema block will be implemented without "results evaluation".

\section{Simulation and Experimental Results}

\subsection{The Experimental Setup}

The experimental research was performed on a large workpiece selected from the common production program of a cooperating industrial company (PHS Hydrotor S.A., Tuchola, Poland), because this is the only way to effectively solve large-size machining problems (Uriarte et al. [43]). The workpiece was made of STW22 03M steel and had a total size of $2061 \times 1116 \times 540 \mathrm{~mm}$ (Figure 3a). Modal tests as well as the succeeding milling operations were performed on the workpiece clamped on a table of the MIKROMAT 20V (VEB Mikromat, Dresden, Germany) portal machining center. An appropriate system of measuring equipment and signal processing was used in the research (Kaliński et al. [45]).

a)

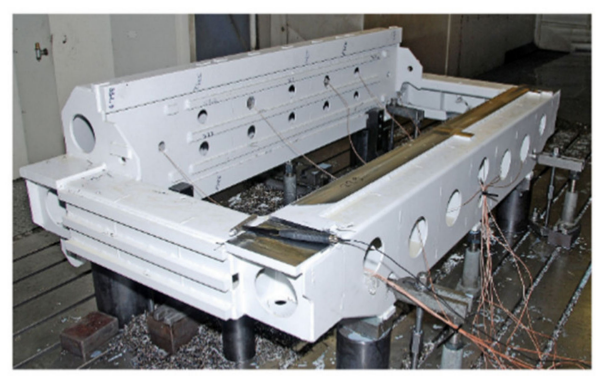

b)

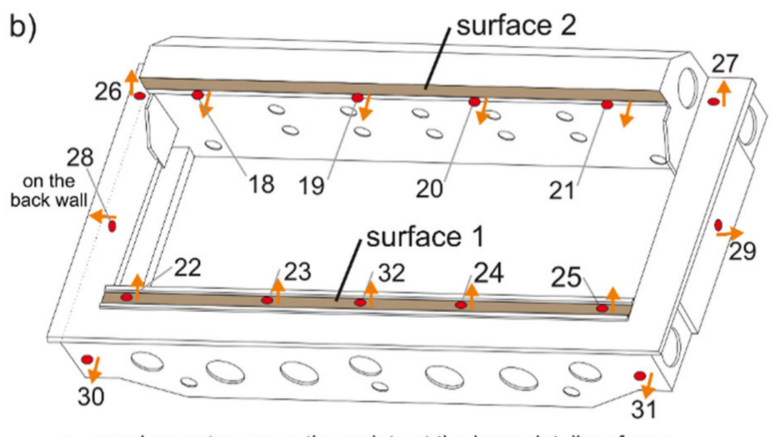

- - accelerometers mounting points at the inner detail surfaces

Figure 3. Test workpiece: (a) clamped on the machine table and (b) simplified scheme of the workpiece with indicated mounting points for accelerometers [45].

Two surfaces of the workpiece were milled (Figure 3b). For surface 1, two passes were performed as one complete operation. In the first pass, i.e., full face milling, the tool (Sandvik R390-044C4-11M060, Sandvik AB, Stockholm, Sweden) moved from the left (i.e., near accelerometer no. 22) to the right. In the second pass, i.e., down milling, the tool moved in the opposite direction (i.e., starting from near accelerometer 25). For surface 2, only one down milling pass was made, with the tool (Sandvik R390-125Q40-17H, Sandvik $\mathrm{AB}$, Stockholm, Sweden) moving from left to right (i.e., starting around accelerometer 18). The primary guideline for selecting measurement points' positions was to enable measuring vibration signals along the milled surfaces. Thus, five DJB A/120/V $\pm 75 \mathrm{~g}$ (DJB Instruments, Suffolk, UK) accelerometers were placed at equal intervals under the first milled surface, and four DJB A/120/V accelerometers under the second one (Figure 3b).

The standard parameters (Kaliński et al. [45]) used in the milling process are derived from the common production scheme of the cooperating industry partner (Table 1). The use of tools with cutting edge angles $\kappa=90^{\circ}$ means that taking into account the bending 
phenomenon of the tool system, typical for relatively large cutter diameters, is not required in the calculation model (Totis et al. [44]). The vibration level observed during milling performed with these parameters was recognized as a reference to the evaluation of the results of the proposed method of searching for the best spindle speed.

Table 1. Data used for the standard milling process of the test workpiece.

\begin{tabular}{|c|c|c|c|c|c|c|c|c|c|c|c|}
\hline \multirow{2}{*}{$\begin{array}{l}\text { Milled } \\
\text { Surface }\end{array}$} & \multirow{2}{*}{$\begin{array}{c}\text { Length } \\
\text { [mm] }\end{array}$} & \multirow{2}{*}{$\begin{array}{l}\text { Type of } \\
\text { Milling }\end{array}$} & \multirow{2}{*}{$\begin{array}{c}B_{1} \\
{[\mathrm{~mm}]}\end{array}$} & \multirow{2}{*}{$\begin{array}{c}B_{2} \\
{[\mathrm{~mm}]}\end{array}$} & \multicolumn{3}{|c|}{ Standard Parameters } & \multicolumn{4}{|c|}{ Milling Cutter } \\
\hline & & & & & $\begin{array}{c}n \\
{[\mathrm{rpm}]}\end{array}$ & $\begin{array}{c}v_{f} \\
{[\mathrm{~mm} / \mathrm{min}]}\end{array}$ & $\begin{array}{c}a_{p} \\
{[\mathrm{~mm}]}\end{array}$ & Type & $z$ & $D[\mathrm{~mm}]$ & $\kappa\left[^{\circ}\right]$ \\
\hline \multirow{2}{*}{1} & \multirow{2}{*}{1778} & Full & 22 & 22 & \multirow{2}{*}{1300} & \multirow{2}{*}{600} & \multirow[t]{2}{*}{1} & $\begin{array}{c}\text { Sandvik } \\
\text { R390-044C4- }\end{array}$ & \multirow{2}{*}{4} & \multirow{2}{*}{44} & \multirow{2}{*}{90} \\
\hline & & Down & & 13.5 & & & & 11M060 & & & \\
\hline 2 & 1789 & Down & & 55 & 560 & 1233 & 1 & $\begin{array}{c}\text { Sandvik R390- } \\
\text { 125Q40-17H }\end{array}$ & 11 & 125 & 90 \\
\hline
\end{tabular}

\subsection{Experimental Modal Identification}

Experimental modal studies of the workpiece were performed for each mounting point of the accelerometers (see Figure 3b) with the use of a PCB 086 C03 (PCB Piezotronics Inc. Depew, NY, USA) modal hammer. Using the polyreference-least squares complex frequency domain (p-LSCFD) method (Kaliński [41], Heylen et al. [63]) applied to forceacceleration FRFs, mod $=7$ dominant natural frequencies and modal damping coefficients for every surface were identified (Table 2). This means that the experimental modal models were correctly determined in the range of frequencies up to $500 \mathrm{~Hz}$.

Table 2. Natural frequencies and modal damping coefficients for identified (EMA) normal modes.

\begin{tabular}{ccccc}
\hline No. & \multicolumn{2}{c}{ Surface 1 } & \multicolumn{2}{c}{ Surface 2 } \\
\hline & $\begin{array}{c}\text { Frequency } \\
{[\mathbf{H z}]}\end{array}$ & $\begin{array}{c}\text { Modal Damping } \\
{[\%]}\end{array}$ & $\begin{array}{c}\text { Frequency } \\
{[\mathbf{H z}]}\end{array}$ & $\begin{array}{c}\text { Modal Damping } \\
{[\%]}\end{array}$ \\
\hline 1 & 172.1 & 0.996 & 91.1 & 9.342 \\
2 & 187.3 & 2.083 & 113.1 & 9.936 \\
3 & 233.0 & 1.618 & 150.8 & 4.542 \\
4 & 253.6 & 0.859 & 173.2 & 0.777 \\
5 & 265.0 & 1.458 & 196.5 & 0.972 \\
6 & 280.4 & 0.902 & 279.2 & 1.572 \\
7 & 373.1 & 1.908 & 307.5 & 1.225 \\
\hline
\end{tabular}

For points located on the machined surface, the modes were scaled to unit modal masses, so that the $\Psi$ matrix of normal modes of the modal subsystem was mass-normalized.

Necessary normal modes of a modal subsystem were computed from complex modes by calculating their amplitudes. Only modes having well stabilized poles in the stability diagram and the low phase deviation (MPC (modal phase collinearity) > 0.85) (Kaliński [41], Maia and Silva [64]) were selected. During identification, only sensors located on the selected surface were considered. All available inputs were utilized, i.e., excitations of every sensor located on the surface. The results obtained for sensors located at a further distance from the excitation place were not taken into consideration during identification. It must be also noted that excitation was applied near every sensor, so that the signal to noise ratio was high. In a given condition, the p-LSCFD method produced reliable results. An important advantage of the p-LSCFD is generally good identification of highly damped poles (Heylen et al. [63]), which was the case for the experimental workpiece used during the impulse tests. The applied modal test and identification procedure focus on the vibration modes important for the milling zone. It naturally eliminates modes that should weekly influence the machined surface dynamics. The selection of sensors placed 
on the machined surface and excitations perpendicular to this surface resulted in obtaining a small number of normal modes, but ones important from the point of view of reliable milling dynamics description.

\subsection{Linear Interpolation}

The number of sensors $j_{s}$ was limited, so these modes are defined for a few points only, not dense enough for the purpose of milling simulations. In order to solve this problem, an original technique was developed that, for given geometrical data of a machined surface, computes displacements for scaled modes identified from modal tests and interpolates them for other surface points. For this purpose, the use of linear interpolation was proposed. The scheme of such linear interpolation of the identified normal mode vector $\Psi_{i}=\operatorname{col}\left(\Psi_{i 1}, \ldots, \Psi_{i j}, \ldots, \Psi_{i j_{s}}\right), i=1 \ldots, \bmod$, for the coordinate value $\xi$ lying between the measuring points $j$ and $j+1$ corresponding to the sensors' positions (Figure 4) shows that the appropriate interpolated value has the following form:

$$
\Psi_{i}(\xi)=\Psi_{i j}+\frac{\xi_{(t)}-\xi_{j}}{\xi_{j+1}-\xi_{j}}\left(\Psi_{i, j+1}-\Psi_{i j}\right)
$$

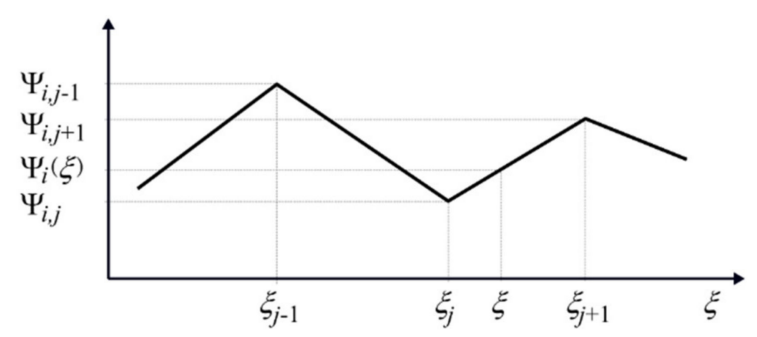

Figure 4. Linear interpolation of the normal mode vector value $\Psi_{i}(\xi)$ for the coordinate $\xi$ between measuring points $j$ and $j+1$.

The values of the vectors of normal modes $\Psi_{i}(\xi), i=1, \ldots$, mod, thus interpolated, can be used to create the matrix of transformation $\mathbf{W}_{l}(t)$ (compare Formula (11)) between the displacement vector in modal coordinates $\mathbf{a}$ and the generalized displacement vector in coordinate system $y_{l 1}, y_{l 2}$, and $y_{l 3}$ of CE no. $l$. It should be noted that, for changing the position of the contact between the edge top of the tool and the workpiece, where $\xi=\xi(t)$, we obtain the following:

$$
\mathbf{W}_{l}(t)=\mathbf{W}_{l}(t, \xi(t))=\left[\begin{array}{cc}
\boldsymbol{\Theta}_{l}(t)_{3 \times 3} & \mathbf{0}_{3 \times 3} \\
\mathbf{0}_{3 \times 3} & \boldsymbol{\Theta}_{l}(t)_{3 \times 3}
\end{array}\right] \mathbf{C}_{W} \hat{\mathbf{\Psi}}(\xi(t)),
$$

where

$\boldsymbol{\Theta}_{l}(t)$-matrix of directional cosines between the axes $y_{l 1}, y_{l 2}$, and $y_{l 3}$ of CE no. $l$, and the axes of the coordinate system $x_{1}, x_{2}$, and $x_{3}$ (Figure 1 );

$$
\begin{aligned}
& \mathrm{C}_{W}=\operatorname{col}(0,0,1,0,0,0) \text {; }
\end{aligned}
$$

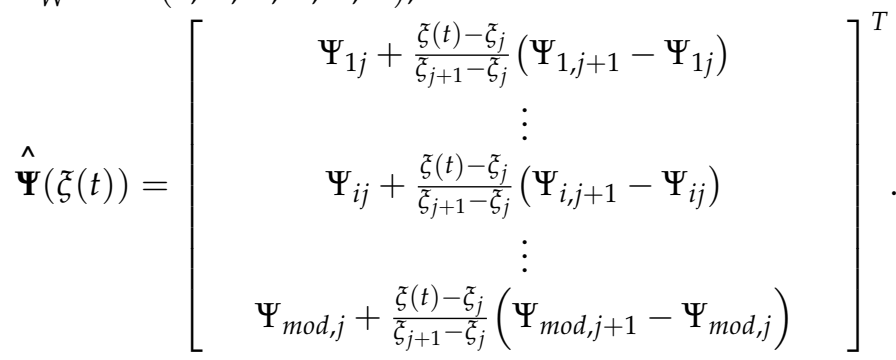

After interpolation or extrapolation (for surface points of the workpiece lying outside sensors' positions), it is possible to obtain these values for a set of points on the machined surface much larger than the set of sensor positions. The observed normal modes were of a low degree, so a mode aliasing was avoided. 
The approximate time to obtain the expected modal model for one surface of the workpiece using a laptop computer equipped with an Intel Core i7-6700HQ 2.60 GHz CPU and 32 GB RAM was about 15 min, which is much shorter than the 240 min needed in the case of assuring compatibility between the modal experimental results and the FEM (Kaliński et al. [45]). The interpolated mass-normalized normal modes for points lying on the machined surface were then exported to the original AMIKRO4 milling process simulation software. Next, the simulations using the modal model based on only seven dominant modes were performed for a set of spindle speeds.

\subsection{Spindle Speed Selection}

According to the approach of searching for the best spindle speed using EAOVP during milling high-sized workpieces (Figure 2), the next phase of this procedure involves simulations of the face milling process of the machined surfaces performed for standard parameters. These simulations utilize a non-stationary calculation model and are performed in order to obtain the compliance of the RMS values of simulated vibrations' displacements with the values measured in standard production conditions. Other milling process model simulations' validation quantities may be used as well. However, the simulated models are non-stationary and strongly non-linear, so the measures usually utilized for steady state vibrations are not applicable here. The concept based on RMS seems to be the best measure of displacement assessment in the studied cases (Kaliński et al. [45]).

One can observe the adjusted parameters $k_{d l}, \mu_{l 2}$, and $\mu_{l 3}$ of the hybrid model used during milling simulation for the nominal spindle speed (i.e., standard milling) in order to satisfy the condition of compliance of the RMS values obtained from machining and the corresponding RMS values of simulated plots (Table 3). In the adopted mechanistic model of cutting forces, the meaning of the above-mentioned coefficients is abstract. Therefore, there is neither an analytical nor an experimental method that would unambiguously allow their value to be determined. All that remains is to estimate them. Owing to the similarity of the analyzed milling operations of a large-size object, the initial values were identical to those considered in Kaliński et al. [45]. After adjusting them, these values differed slightly from the initially adopted ones.

Table 3. Milling features and adjusted parameters for the process simulation.

\begin{tabular}{|c|c|c|c|c|c|c|c|c|c|c|}
\hline \multirow{2}{*}{$\begin{array}{l}\text { Milled } \\
\text { Surface }\end{array}$} & \multirow{2}{*}{$\begin{array}{l}\text { Type of } \\
\text { Milling }\end{array}$} & \multicolumn{4}{|c|}{ Milling Features } & \multicolumn{4}{|c|}{ Adjusted Parameters } & \multirow{2}{*}{$\begin{array}{l}\text { Simulation } \\
\text { Time [min] }\end{array}$} \\
\hline & & $\begin{array}{c}n \\
{[\mathrm{rpm}]}\end{array}$ & $\begin{array}{c}v_{c} \\
{[\mathrm{~m} / \mathrm{min}]}\end{array}$ & $\begin{array}{c}v_{f} \\
{[\mathrm{~mm} / \mathrm{min}]}\end{array}$ & $\begin{array}{l}\text { RMS } \\
{[\mathrm{mm}]}\end{array}$ & $\begin{array}{c}k_{d l} \\
{\left[\mathrm{daN} / \mathrm{mm}^{2}\right]}\end{array}$ & $\mu_{12}$ & $\mu_{l 3}$ & $\begin{array}{c}\text { Adjustment } \\
\text { Time [min] }\end{array}$ & \\
\hline 1 & $\begin{array}{l}\text { Full: } \\
\text { standard } \\
\text { range } \\
\text { the best }\end{array}$ & $\begin{array}{c}1300 \\
1300-1500 \\
1500\end{array}$ & $\begin{array}{c}180 \\
180-207 \\
207\end{array}$ & $\begin{array}{c}600 \\
600-692 \\
692\end{array}$ & $\begin{array}{l}0.000289 \\
0.000254\end{array}$ & $\begin{array}{l}500 \\
500 \\
500\end{array}$ & $\begin{array}{l}0.40 \\
0.40 \\
0.40\end{array}$ & $\begin{array}{l}0.58 \\
0.58 \\
0.58\end{array}$ & 3 & 20 \\
\hline 2 & $\begin{array}{c}\text { Down: } \\
\text { standard } \\
\text { range } \\
\text { the best }\end{array}$ & $\begin{array}{c}560 \\
550-800 \\
700\end{array}$ & $\begin{array}{c}220 \\
220-314 \\
275\end{array}$ & $\begin{array}{l}1233 \\
1211- \\
1761 \\
1541\end{array}$ & 0.002958 & $\begin{array}{l}500 \\
500 \\
500\end{array}$ & $\begin{array}{l}0.40 \\
0.40 \\
0.40\end{array}$ & $\begin{array}{l}0.40 \\
0.40 \\
0.40\end{array}$ & 2 & 20 \\
\hline
\end{tabular}

Milling simulations were performed for a specific spindle speed range. Spindle speeds below the lower limits of the adopted ranges were omitted, because the selection of the best spindle speed was to result not only in a reduction of the vibration level, but also in an increase in the efficiency of the milling process.

For each simulated spindle speed, the vibration level was observed and three indicators were calculated, which are presented in the appropriate figures. These are as follows (Kaliński et al. [45]): $R M S_{95 \%}$, i.e., RMS of relative tool-workpiece displacements calculated for $95 \%$ of the entire cutting time; $A_{m a x}$, i.e., the maximum amplitude of relative tool-workpiece displacements calculated for the same period as for $\mathrm{RMS}_{95 \%}$; and 
$R M S_{95 \%}$ MR, i.e., RMS of relative tool-workpiece displacements calculated for $95 \%$ of the whole total cutting time, but in relation to the average value of the considered vibrations (MR -related to the average). The latter index (analogous to the standard deviation of vibration) can be interpreted as an indicator of the vibration level relative to the static displacement of the workpiece surface caused by the action of the tool. This corresponds best to the piezoelectric accelerometer method of measuring vibration during the actual milling process, when low frequency vibrations and static deflections are ignored.

Based on the simulations performed, the best spindle speed was selected for surface 1 (Figure 5) and appropriate plots of the simulation results, at the standard and best spindle speeds, are presented in Figure 6. Similarly the best spindle speed was selected for surface 2 (Figure 7) and relevant plots of the simulation results are presented in Figure 8. The predicted RMS values for the best spindle speeds are shown in Table 3. Subsequently, such best parameters were used for milling processes, whose results are presented and discussed in the next subsection.

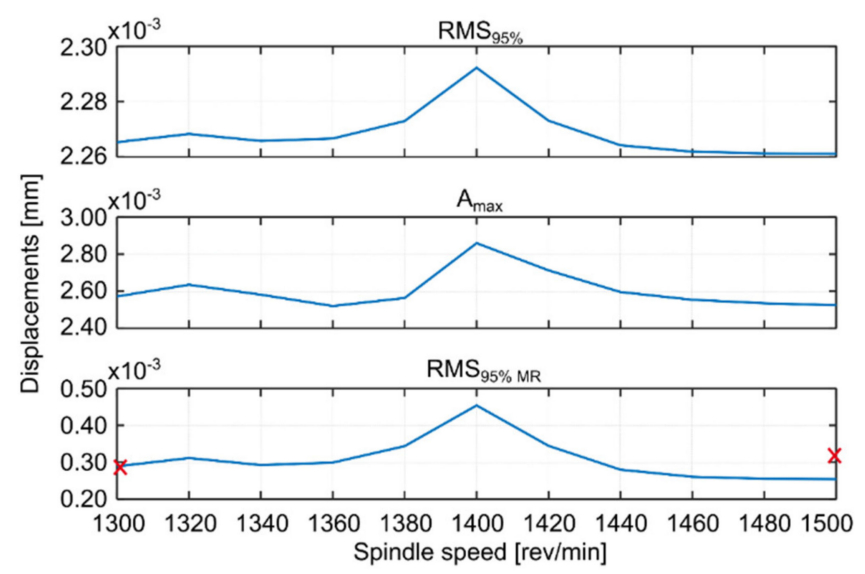

Figure 5. EAOVP for full milling of the workpiece, surface 1, indices values with respect to the simulated spindle speed, $\mathrm{x}$-average results of measurements.

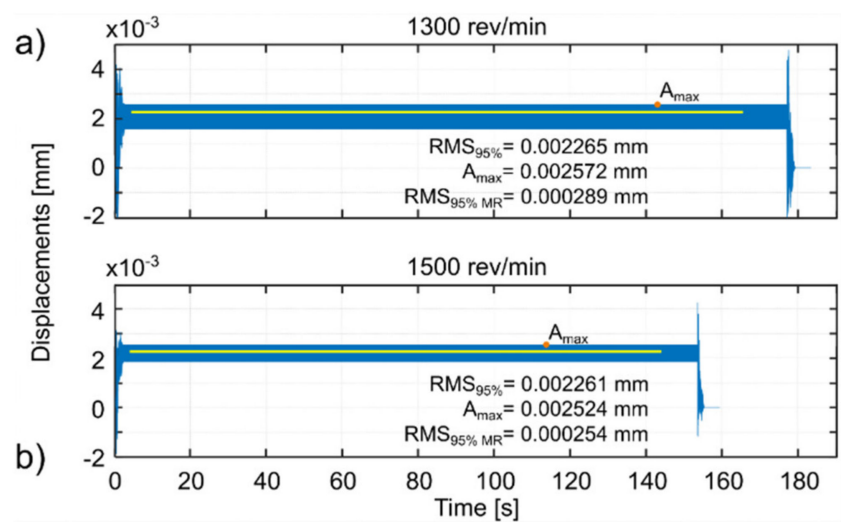

Figure 6. EAOVP, simulation results for full milling of surface 1 at (a) the standard spindle speed of $1300 \mathrm{rev} / \mathrm{min}$ and $(\mathbf{b})$ the best spindle speed of $1500 \mathrm{rev} / \mathrm{min}$. 


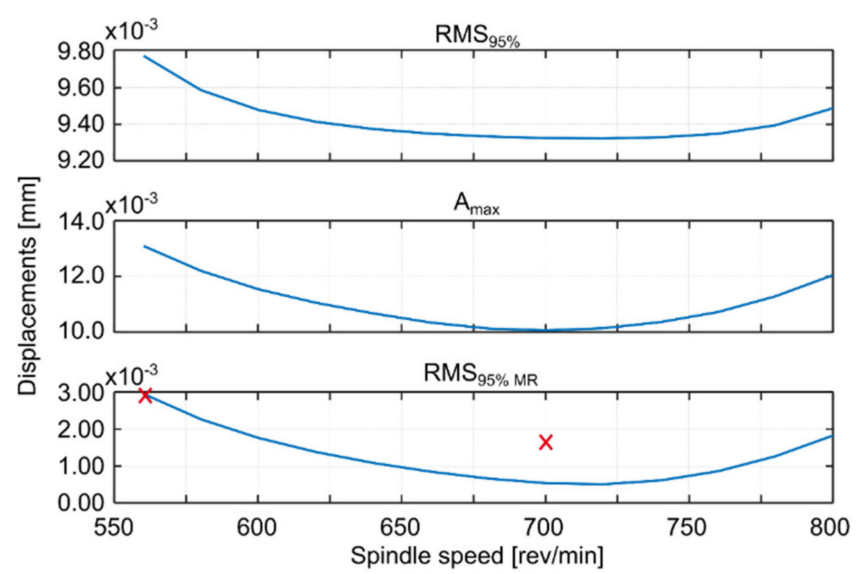

Figure 7. EAOVP for down milling of the workpiece, surface 2, indices values with respect to the simulated spindle speed, $\mathrm{x}$-average results of measurements.

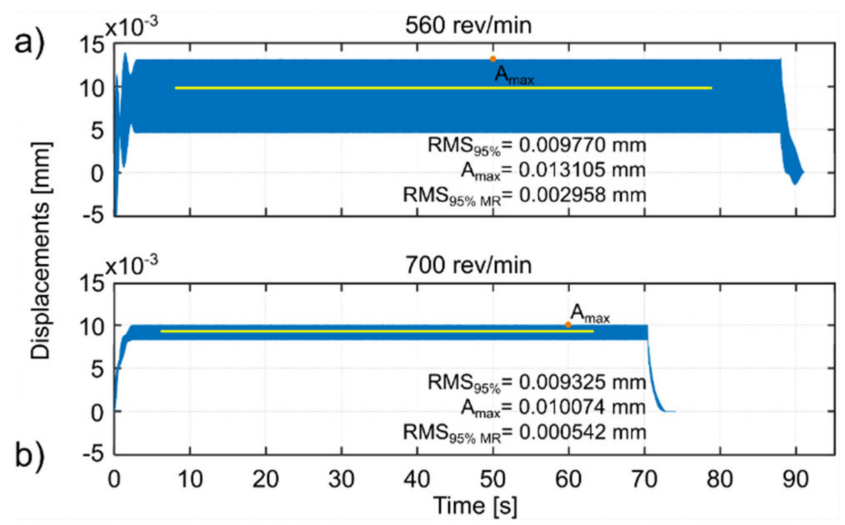

Figure 8. EAOVP, simulation results for down milling of surface 2 at (a) the standard spindle speed of $560 \mathrm{rev} / \mathrm{min}$ and $(\mathbf{b})$ the best spindle speed of $700 \mathrm{rev} / \mathrm{min}$.

The proposed method uses modal test results directly. This saves a lot of time and the requirements for the measuring equipment used can also be lower. For example, there is no need for time-consuming extensive modal tests of the whole workpiece structure and the complicated FEM correlation (Kaliński et al. [45]). Milling simulations are performed for a simplified hybrid model, which are faster than in the case of full FEM of the workpiece and support. When the full FEM is utilized, it is often difficult to predict which modes will be important during milling, so a greater number of them must be taken into account. Meanwhile, frequencies of normal modes identified in a modal test are more accurate than those calculated from FEM, even if the FEM is very well correlated. In the EAOVP, during analysis of the respective machined surface, only data for points lying on the selected surface are taken into consideration. Thanks to this, analyses are mainly performed for high quality signals, ignoring weakly excited modes and measurement points that have low influence on the subjected modes. Moreover, it can be difficult to obtain, on the basis of the latter, promising results on massive objects mounted on a milling machine with the help of numerous supports and clamps.

The proposed method provides a solution that improves the milling process in such a way that the vibration level of the workpiece approaches the minimum (compare Figures 5 and 7).

\subsection{Real Milling Results}

Milling operations were performed for both surfaces of the workpiece, with spindle speeds selected according to standard parameters and the method presented in this paper. Table 4 presents the selected milling parameters, wherein the selection of the best speed 
corresponds to that obtained from simulations based on the EAOVP. In Tables 5 and 6, the sign "Axx" represents the number of the indicated accelerometer (see Figure $3 b$ ). In turn, Table 5 shows the RMS values of displacements for the milling operations performed, observed at the measurement points while moving the tool over the surroundings of a given accelerometer. The displacements values in Figures 9-14 are presented as the results of double integration of the measured accelerations (during integration, the signal was filtered with an ideal high-pass filter with a cutoff frequency of $20 \mathrm{~Hz}$ ). Table 6 presents the same data, but as relative values, to help note the better results provided towards vibration suppression by the proposed approach, wherein the vibration reduction is marked with a “-" sign.

Table 4. Spindle and feed speeds selected for milling the real workpiece.

\begin{tabular}{ccccccc}
\hline $\begin{array}{c}\text { Speed } \\
\text { Selection }\end{array}$ & \multicolumn{3}{c}{ Surface $\mathbf{1}$} & \multicolumn{2}{c}{ Surface 2 } \\
\cline { 2 - 7 } & $\begin{array}{c}\boldsymbol{a}_{\boldsymbol{p}} \\
{[\mathbf{m m}]}\end{array}$ & $\begin{array}{c}\text { Spindle Speed } \\
\boldsymbol{n} \text { [rev/min] }\end{array}$ & $\begin{array}{c}\text { Feed Speed } \boldsymbol{v}_{f} \\
{[\mathbf{m m} / \mathbf{m i n}]}\end{array}$ & $\begin{array}{c}\boldsymbol{a}_{\boldsymbol{p}} \\
{[\mathbf{m m}]}\end{array}$ & $\begin{array}{c}\text { Spindle Speed } \\
\boldsymbol{n} \text { [rev/min] }\end{array}$ & $\begin{array}{c}\text { Feed Speed } v_{f} \\
{[\mathbf{m m} / \mathbf{m i n}]}\end{array}$ \\
\hline Standard & 1 & 1300 & 600 & 1 & 560 & 1233 \\
The best & 1 & 1500 & 692 & 1 & 700 & 1541 \\
\hline
\end{tabular}

Table 5. RMS values of displacements of performed milling operations for measurement points on the milled surfaces.

\begin{tabular}{|c|c|c|c|c|c|c|c|}
\hline \multicolumn{8}{|c|}{ Surface 1} \\
\hline \multirow{2}{*}{$\begin{array}{l}\text { Milling } \\
\text { Type }\end{array}$} & \multirow{2}{*}{$\begin{array}{c}\text { Speed } \\
\text { Selection }\end{array}$} & \multicolumn{6}{|c|}{ Displacements RMS [mm] } \\
\hline & & A22 & A23 & A32 & A24 & A25 & Average \\
\hline \multirow{2}{*}{ Full } & Standard & 0.000128 & 0.000340 & 0.000432 & 0.000390 & 0.000144 & 0.000287 \\
\hline & $\begin{array}{c}\text { Standard } \\
\text { - simulation - }\end{array}$ & & & & & & 0.000289 \\
\hline Down & Standard & 0.000275 & 0.001376 & 0.001581 & 0.001281 & 0.000261 & 0.000955 \\
\hline \multirow[t]{2}{*}{ Full } & $\begin{array}{c}\text { The best } \\
\text { - prediction - }\end{array}$ & & & & & & 0.000254 \\
\hline & The best & 0.000209 & 0.000318 & 0.000410 & 0.000364 & 0.000252 & 0.000311 \\
\hline Down & The best & 0.000380 & 0.000545 & 0.000687 & 0.000592 & 0.000357 & 0.000512 \\
\hline \multicolumn{8}{|c|}{ Surface 2} \\
\hline & & A18 & A19 & A20 & & & Average \\
\hline \multirow{2}{*}{ Down } & Standard & 0.003817 & 0.003105 & 0.002825 & & & 0.002965 \\
\hline & $\begin{array}{c}\text { Standard } \\
\text { - simulation - }\end{array}$ & & & & & & 0.002958 \\
\hline \multirow[t]{2}{*}{ Down } & $\begin{array}{c}\text { The best } \\
\text { - prediction - }\end{array}$ & & & & & & 0.000542 \\
\hline & The best & 0.001537 & 0.001474 & 0.001562 & & & 0.001528 \\
\hline
\end{tabular}


Table 6. Relative change in RMS values of displacements of performed milling operations for measurement points on the milled surfaces. The standard spindle speed milling is taken as the reference.

\begin{tabular}{|c|c|c|c|c|c|c|c|}
\hline \multirow{3}{*}{$\begin{array}{l}\text { Milling } \\
\text { Type }\end{array}$} & \multicolumn{6}{|c|}{ Surface 1} & \\
\hline & \multirow{2}{*}{$\begin{array}{c}\text { The Best Spindle Speed } \\
\text { Selection }\end{array}$} & \multicolumn{6}{|c|}{ Change in RMS Values [\%] } \\
\hline & & A22 & A23 & A32 & A24 & A25 & Average \\
\hline \multirow{3}{*}{ Full } & Prediction EAOVP & & & & & & -12.1 \\
\hline & Milling EAOVP & 63.3 & -6.5 & -5.1 & -6.7 & 75.0 & 8.3 \\
\hline & Milling EAVP & 35.9 & -31.8 & -25.9 & -21.8 & 41.0 & -13.9 \\
\hline \multirow{2}{*}{ Down } & Milling EAOVP & 38.2 & -60.4 & -56.5 & -53.8 & 36.8 & -46.4 \\
\hline & Milling EAVP & 8.4 & -63.7 & -57.6 & -54.4 & 25.3 & -50.1 \\
\hline \multicolumn{8}{|c|}{ Surface 2} \\
\hline & & A18 & A19 & A20 & \multicolumn{2}{|c|}{$\mathrm{A} 21$} & Average \\
\hline \multirow{3}{*}{ Down } & Prediction EAOVP & & & & & & -81.7 \\
\hline & Milling EAOVP & -59.7 & -52.5 & -44.7 & \multicolumn{2}{|c|}{-27.2} & -48.5 \\
\hline & Milling EAVP & -48.7 & -37.2 & 7.6 & \multicolumn{2}{|c|}{-33.2} & $\begin{array}{l}-42.2 \\
-13.8\end{array}$ \\
\hline
\end{tabular}

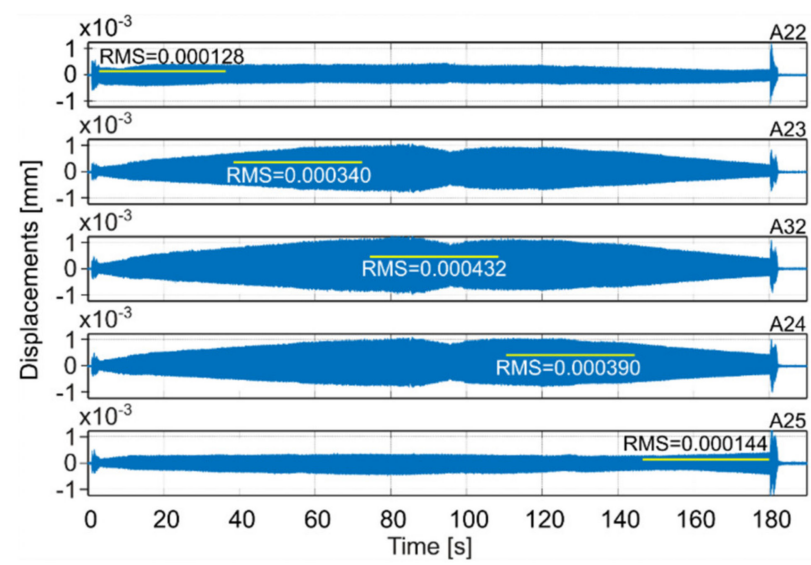

Figure 9. Vibrations of the workpiece during full milling of surface 1 at standard parameters (see Table 4) [45].

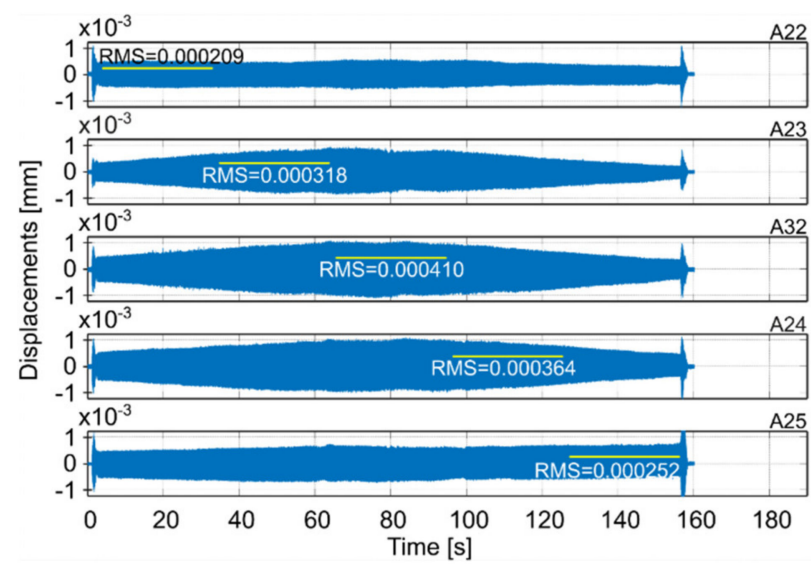

Figure 10. Vibrations of the workpiece during full milling of surface 1 at the best parameters (see Table 4). 


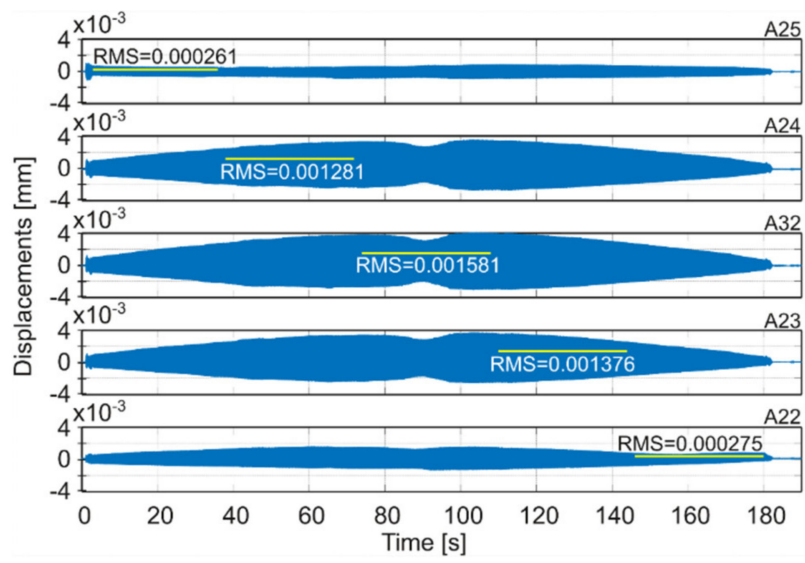

Figure 11. Vibrations of the workpiece during down milling of surface 1 at standard parameters (see Table 4).

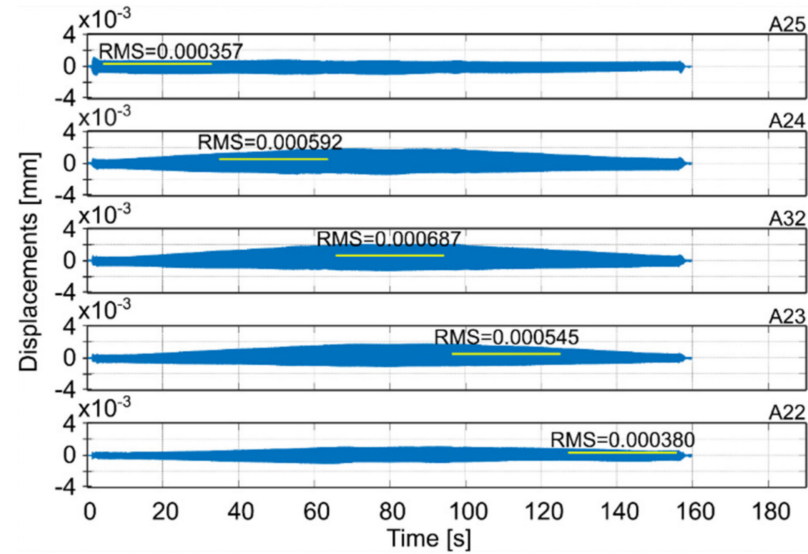

Figure 12. Vibrations of the workpiece during down milling of surface 1 at the best parameters (see Table 4).

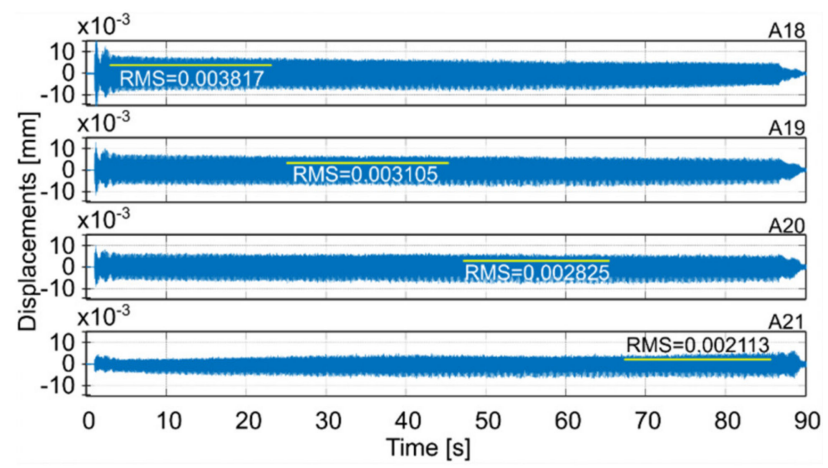

Figure 13. Vibrations of the workpiece during down milling of surface 2 at standard parameters (see Table 4). 


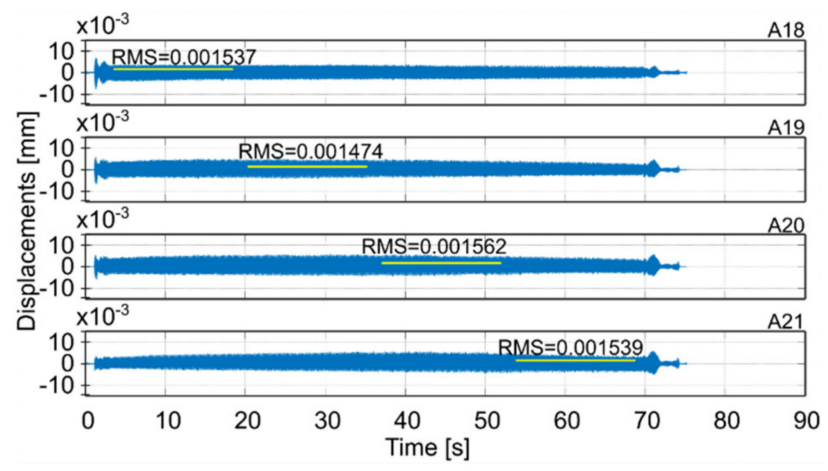

Figure 14. Vibrations of the workpiece during down milling of surface 2 at the best parameters (see Table 4).

As mentioned earlier, the milling results with standard parameters were treated as a reference for further tests. The presented method for selecting the best spindle speed has been successfully tested.

The use of the EAOVP to milling surfaces 1 and 2 leads to a slight underestimation of all the predicted results in relation to the measured average vibration displacements, in each milling case (Figures 5 and 7, Table 5). However, the above is irrelevant because the most important thing is that this approach gave better milling results than with the standard types and, moreover, in a significantly shorter time.

Compared with the standard technology (Table 6), in the case of milling surface 1, a significant reduction in the vibration level (RMS displacement) was achieved in the down milling type (by $46.4 \%$ ), and in the case of full milling, a slight increase in RMS vibrations by $8.3 \%$. The above was accompanied by an increase in the spindle speed by $15 \%$ (Table 4 ), which made it possible to shorten the main time of the removal of the allowance (two passes) by $0.79 \mathrm{~min}$, i.e., by $13 \%$. In the case of milling surface 2 , an increase in spindle speed of $25 \%$ was achieved (Table 4 ), with a significant reduction in RMS vibrations of $48.5 \%$ (Table 6), which resulted in a reduction in the main time of the pass of $0.29 \mathrm{~min}$, i.e., by $20 \%$.

Table 6 also presents a comparison of the relative changes in the RMS value during milling operations obtained with the EAOVP method proposed in the current article and the EAVP method described earlier by Kaliński et al. [45]. For full milling of surface 1, the average RMS value increased slightly, although not significantly. On the other hand, during down milling, the reduction in the average RMS value is comparable in both methods. Further, in the case of milling surface 2, it is even more effective. The above proves that the required accuracy of surface treatment is actually met.

\subsection{Assessment of the Profitability of the EAOVP}

In order to estimate the profitability resulting from the implementation of the developed innovative solution, the relevant production standards of technological times were compared (Feld [65]). So, let us analyze the reconsidered process of face milling of the large workpiece surfaces on the MIKROMAT 20V portal machining center, where two passes are performed per surface 1, i.e., full milling and down milling, and one pass per surface 2 (see Section 4.1). According to the standard technology, such processing has so far been performed with a time per unit (approximately equal to the operation time), which, for three passes, is as follows:

$$
t_{j}=2 \times\left(l_{p k 1,2} \times t_{p k 1,2}+t_{g 1,2}\right)+l_{p k 3} \times t_{p k 3}+t_{g 3}
$$

where

- $\quad l_{p k 1,2}$-number of inspection cuts for pass 1 and 2 ;

- $\quad t_{p k 1,2}$ - time of inspection cut of pass 1 and 2;

- $\quad t_{g 1,2}$-main time of pass 1 and 2; 
- $\quad l_{p k 3}$-number of inspection cuts for pass 3;

- $\quad t_{p k 3}$-time of inspection cut of pass 3;

- $\quad t_{g 3}$-main time of pass 3.

For the sake of simplicity, other components of the auxiliary time $t_{p}$ were omitted in Formula (14). Assuming $l_{p k 1,2}=l_{p k 3}=1, t_{p k 1,2}=t_{g 1,2}=2.96 \mathrm{~min}, t_{p k 3}=t_{g 3}=1.44 \mathrm{~min}$, we get $t_{j}=14.72 \mathrm{~min}$.

In the implementation of the proposed innovative solution, the main time of pass 1 and 2 is $t_{g 1,2}=2.57 \mathrm{~min}$, that of pass $3-t_{g 3}=1.15 \mathrm{~min}$, and there are no inspection cuts $\left(l_{p k 1,2}=l_{p k 3}=0\right)$. This gives the total unit time of three passes $t_{j}=6.29 \mathrm{~min}$, which is $57 \%$ shorter.

The total time for machining $w$ workpieces, with three passes per unit, is thus as follows:

- $\quad$ in the case of standard technology $-14.72 \times w$ min;

- $\quad$ in the case of the proposed innovative technology $-6.29 \times w \mathrm{~min}$.

The processing time in the case of the proposed innovative technology should be increased by the time of experimental modal analysis (EMA) and linear interpolation for each surface of only the first workpiece, i.e., $2 \times$ approximately $15 \mathrm{~min}$, and the time of two parallel simulation series for each surface, in order to determine the parameters of the hybrid model and the best spindle speed, i.e., approximately $23 \mathrm{~min}$.

The required number of workpieces, $w$, satisfying the condition of profitability in terms of machining time, results from the following inequality:

$$
14.72 w \geq 6.29 w+2 \times 15+23,
$$

which gives $w \geq 6.29$. Thus, the minimum time-effective number of workpieces to be made is $w=7$.

However, in the implementation of the former solution by the EAVP method (Kaliński et al. [45]), the main time of pass 1 and 2 is $t_{g 1,2}=2.79 \mathrm{~min}$, that of pass 3 is $t_{g 3}=1.09 \mathrm{~min}$, and there are no inspection cuts $\left(l_{p k 1,2}=l_{p k 3}=0\right)$. This gives the total unit time of three passes $t_{j}=6.67 \mathrm{~min}$, which is $55 \%$ shorter.

The total time for machining $w$ workpieces, with three passes per unit, is thus as follows:

- $\quad$ in the case of standard technology $-14.72 \times w \mathrm{~min}$;

- $\quad$ in the case of the EAVP method-6.67 $\times w$ min.

The processing time in the case of the EAVP method should be increased by the time of theoretical (i.e., by the finite element method) and experimental modal analysis (EMA) of only the whole first workpiece, i.e., approximately $240 \mathrm{~min}$, and the time of two parallel simulation series for each surface, in order to determine the parameters of the hybrid model and the best spindle speed, i.e., approximately $30 \mathrm{~min}$.

The required number of workpieces, $w$, satisfying the condition of profitability in terms of machining time, results from the following inequality:

$$
14.72 w \geq 6.67 w+240+30
$$

which gives $w \geq 33.54$. Thus, the minimum time-effective number of workpieces to be made is $w=34$. As the mechanical processing of large-size items in production companies usually concerns small series, the number of which does not exceed 15 items, the proposed EAOVP method is thus more economically viable than the previously proposed EAVP.

The profitability resulting from the implementation of the developed innovative solution, i.e., EAOVP, is thus perceived to be in the category of the following:

- $\quad$ Optimizing the vibration level of the workpiece, leading to improved product quality;

- Determining the minimum time-effective number of workpieces to be made, i.e., $w=7$; 
- Reduction in the cost of the removed material by $50 \%$ owing to the lack of inspection cuts, the number of which in the standard technology is equal to the number of working cuts.

\section{Conclusions}

The EAOVP technique based on linear interpolation has proven successful in determining the best spindle speed for face milling of large-size flexible workpieces, in terms of minimizing the level of tool-workpiece vibrations. The results were achieved in less time by eliminating several time-consuming steps. The latter concerns, for example, no need to create FEM and validate modal parameters.

The essence of the proposed method lies in the effective search, within the accepted range of spindle speeds, of the best speed value for which the tool-workpiece vibration level in the milling of the selected surface reaches a minimum. The above does not imply the complete elimination of vibrations (which is impossible anyway), but a significant reduction in their level. The relationship between minimizing the vibration level of the tool-workpiece in large-size machining and the quality of the treated surface has been proven in many scientific elaborations (e.g., Liu et al. [18]). It is also the result of industrial research conducted by the authors (Kaliński et al. [45]). Therefore, the search for a spindle speed value that satisfies the minimization of the vibration level should have a positive impact on the quality of the milled surface.

The full milling type is much better dynamically conditioned, as evidenced by the RMS value of the vibration level at both the standard and the best spindle speed. Hence, the effectiveness of the surveillance, measured by RMS values in both cases, is not that noticeable. On the other hand, in the case of down milling, much less conditioned and much higher RMS values are observed, especially during milling surface 2 . Hence, a much better improvement in these values proves the usefulness of the method proposed in the article.

The advantage of EAOVP is a much shorter time to obtain the best spindle speed than in the case of the classic EAVP (Kaliński et al. [45]), which makes it more suitable for use in the practice of production enterprises. The absence of a full FEM in the approach saves time both in building the model and in adapting it to the results of experimental modal tests. With EAOVP, modal tests are also easier and take less time, and you can use fewer measurement points. After all, the tests are limited only to the surfaces to be machined. The assessment of the profitability of implementing the proposed innovative approach should be considered in the category of optimizing the vibration level of the workpiece, resulting in an improvement in the quality of workmanship, as well as a significant reduction in the production standard of the unit execution time. In addition, the reduction in material costs to be removed cannot be overestimated owing to the absence of inspection cuts, a significant number of which actually exist in standard technology.

The selection of the best technological parameters of the machining process through experimental material tests when milling large-size workpieces is time-consuming, expensive, and ineffective. The proposed EAOVP technique meant that the basis for the selection of the best spindle speed was the results of a computer simulation of the computational model, the parameters of which were identified only by the experimental modal analysis (EMA). The number of material machining experiments was limited to two for each surface, i.e., the standard (matching the parameter values to the results of the cutting process simulation) and the best (confirming the effectiveness of the computer prediction).

Author Contributions: Conceptualization, K.J.K.; methodology, K.J.K. and M.R.M.; software, K.J.K., M.A.G. and N.S.-M.; investigation, K.J.K., M.R.M., M.A.G. and. N.S.-M.; data curation, M.A.G. and N.S.-M.; writing—original draft preparation, K.J.K. and M.A.G.; writing—review and editing, K.J.K., M.A.G., M.R.M. and N.S.-M.; visualization, M.A.G.; supervision, K.J.K.; project administration, K.J.K.; funding acquisition, K.J.K. All authors have read and agreed to the published version of the manuscript. 
Funding: The research has been performed as a part of the tasks financed by the Polish National Centre for Research and Development, project TANGO1/266350/NCBR/2015, on "Application of chosen mechatronic solutions to surveillance of the large-size workpieces cutting process on multi axial machining centers".

Institutional Review Board Statement: Not applicable.

Informed Consent Statement: Not applicable.

Data Availability Statement: The data presented in this study are available on reasonable request from the corresponding author.

Acknowledgments: Experimental investigations on the MIKROMAT 20V portal machining center were performed thanks to cooperation with the PHS HYDROTOR Inc. in Tuchola, Poland.

Conflicts of Interest: The authors declare no conflict of interest.

\section{Appendix A}

1. Inertia matrix of the structural subsystem:

$$
\mathbf{M}=\operatorname{diag}\left(m, m, m, J_{x r 1}, J_{x r 2}, J_{x r 2}\right),
$$

$m$-mass of the RFE, $J_{x r 1}$-mass moment of inertia with respect to the $x_{r 1}$ axis of the RFE, $J_{x r 2}$-mass moment of inertia with respect to the $x_{r 2}$ axis of the RFE, and $J_{x r 3}$ - mass moment of inertia with respect to the $x_{r 3}$ axis of the RFE.

2. Damping matrix of the structural subsystem:

$$
\mathbf{L}=\mathbf{S}_{r k}^{T} \mathbf{L}_{k} \mathbf{S}_{r k}
$$

$\mathbf{S}_{r k}$, - matrix of coordinates of the SDE attachment point in local coordinate system $x_{r 1}, x_{r 2}$, and $x_{r 3}$ of the RFE,

$$
\mathbf{S}_{r k}=\left[\begin{array}{cccccc}
1 & 0 & 0 & 0 & S_{r k 3} & S_{r k 2} \\
0 & 1 & 0 & S_{r k 3} & 0 & S_{r k 1} \\
0 & 0 & 1 & S_{r k 2} & S_{r k 1} & 0 \\
0 & 0 & 0 & 1 & 0 & 0 \\
0 & 0 & 0 & 0 & 1 & 0 \\
0 & 0 & 0 & 0 & 0 & 1
\end{array}\right],
$$

$\mathbf{L}_{k}=\operatorname{diag}\left(l_{k i}\right), i=1, \ldots, 6$-matrix of damping coefficients of the SDE.

3. Stiffness matrix of the structural subsystem:

$$
\mathbf{K}=\mathbf{S}_{r k}^{T} \mathbf{K}_{k} \mathbf{S}_{r k}
$$

$\mathbf{K}_{k}=\operatorname{diag}\left(k_{k i}\right), i=1, \ldots, 6$-matrix of stiffness coefficients of the SDE.

4. Transformation matrix of displacements vector $\mathbf{q}$ from the $x_{r 1}, x_{r 2}$, and $x_{r 3}$ coordinates of the RFE, to the coordinate system $y_{l 1}, y_{l 2}$, and $y_{l 3}$ of CE no. $l$ :

$$
\begin{gathered}
\mathbf{T}_{l}(t)=\boldsymbol{\Theta}_{r l}(t) \mathbf{S}_{r l}(t), \\
\boldsymbol{\Theta}_{r l}(t)=\left[\begin{array}{cc}
\boldsymbol{\Theta}_{r l}^{*}(t) & 0 \\
0 & \boldsymbol{\Theta}_{r l}^{*}(t)
\end{array}\right],
\end{gathered}
$$

$\boldsymbol{\Theta}_{r l}^{*}(t)=\left[\cos _{r l i j}(t)\right]_{3 \times 3}$-matrix of direction cosines of time varying angles $\alpha_{r l i j}(t)$ between axis $y_{l i}$ of CE no. $l$ and axis $x_{r j}$ of the RFE, $i=1, \ldots, 3, j=1, \ldots, 3$; $\mathrm{S}_{r l}(t)$-matrix of variable-time coordinates of the attachment point of CE no. $l$ in local coordinates system $x_{r 1}, x_{r 2}$, and $x_{r 3}$ of the RFE (similar to A3). 


\section{References}

1. Fei, J.; Xu, F.; Lin, B.; Huang, T. State of the art in milling process of the flexible workpiece. Int. J. Adv. Manuf. Technol. 2020, 109, 1695-1725. [CrossRef]

2. Hao, X.; Li, Y.; Zhao, Z.; Liu, C. Dynamic machining process planning incorporating in-process workpiece deformation data for large-size aircraft structural parts. Int. J. Comp. Integ. Manuf. 2019, 32, 136-147. [CrossRef]

3. Płodzień, M.; Żyłka, Ł.; Sułkowicz, P.; Żak, K.; Wojciechowski, S. High-Performance Face Milling of 42CrMo4 Steel: Influence of Entering Angle on the Measured Surface Roughness, Cutting Force and Vibration Amplitude. Materials 2021, 14, 2196. [CrossRef] [PubMed]

4. Quintana, G.; Ciurana, J. Chatter in machining processes: A review. Int. J. Mach. Tools Manuf. 2011, 51, 363-376. [CrossRef]

5. Mane, I.; Gagnol, V.; Bouzgarrou, B.C.; Ray, P. Stability-based spindle speed control during flexible workpiece high-speed milling. Int. J. Mach. Tools Manuf. 2007, 48, 184-194. [CrossRef]

6. López de Lacalle, L.N.; Campa, F.J.; Lamikiz, A. Milling. In Mod. Mach. Technol.; Woodhead Publishing: Cambridge, UK, 2011; pp. 213-303. [CrossRef]

7. Urbikain, G.; Campa, F.-J.; Zulaika, J.-J.; López de Lacalle, L.-N.; Alonso, M.-A.; Collado, V. Preventing chatter vibrations in heavy-duty turning operations in large horizontal lathes. J. Sound Vib. 2015, 340, 317-330. [CrossRef]

8. Nouari, M.; List, G.; Girot, F. Wear mechanisms in dry machining of aluminium alloys. Int. J. Mech. Prod. Sys. Eng. 2003, 4, 22-29.

9. Li, X.P.; Wong, Y.S.; Nee, A.Y.C. Tool wear and chatter detection using the coherence function of two crossed accelerations. Int. J. Mach. Tools Manuf. 1997, 37, 425-435. [CrossRef]

10. Munoa, J.; Beudaert, X.; Dombovari, Z.; Altintas, Y.; Budak, E.; Brecher, C.; Stepan, G. Chatter suppression techniques in metal cutting. CIRP Ann. Manuf. Technol. 2016, 65, 785-808. [CrossRef]

11. Yue, C.; Gao, H.; Liu, X.; Liang, S.Y.; Wang, L. A review of chatter vibration research in milling. Chin. J. Aeronaut. 2019, 32, 215-242. [CrossRef]

12. Zhu, L.; Liu, C. Recent progress of chatter prediction, detection and suppression in milling. Mech. Sys. Sig. Proc. 2020, 143, 106840. [CrossRef]

13. Tehranizadeh, F.; Berenji, K.R.; Budak, E. Dynamics and chatter stability of crest-cut end mills. Int. Mach. Tools Manuf. 2021, 171, 103813. [CrossRef]

14. Liu, H.; Zhou, Y. Review of research on chatter stability in milling of thin-walled parts. In Proceedings of the 2020 3rd World Conference on Mechanical Engineering and Intelligent Manufacturing, WCMEIM 2020, Shanghai, China, 4-6 December 2020; pp. 175-178.

15. Campa, F.J.; Lopez de Lacalle, L.N.; Celaya, A. Chatter avoidance in the milling of thin floors with bull-nose end mills: Model and stability diagrams. Int. J. Mach. Tools Manuf. 2011, 51, 43-53. [CrossRef]

16. Dang, X.-B.; Wan, M.; Zhang, W.-H.; Yang, Y. Stability analysis of the milling process of the thin floor structures. Mech. Syst. Signal Process. 2022, 165, 108311. [CrossRef]

17. Yang, Y.; Zhang, W.-H.; Ma, Y.-C.; Wan, M.; Dang, X.-B. An efficient decomposition-condensation method for chatter prediction in milling large-scale thin-walled structures. Mech. Syst. Signal Process. 2019, 121, 58-76. [CrossRef]

18. Liu, D.; Luo, M.; Urbikain, G.; Olvera Trejo, D.; Zhang, D. Position-oriented process monitoring in milling of thin-walled parts. J. Manuf. Syst. 2021, 60, 360-372. [CrossRef]

19. Ren, S.; Long, X.; Meng, G. Dynamics and stability of milling thin walled pocket structure. J. Sound Vib. 2018, 429, 325-347. [CrossRef]

20. Artetxe, E.; Olvera, D.; López de Lacalle, L.N.; Campa, F.J.; Olvera, D.; Lamikiz, A. Solid subtraction model for the surface topography prediction in flank milling of thin-walled integral blade rotors (IBRs). Int. J. Adv. Manuf. Technol. 2017, 90, 741-752. [CrossRef]

21. Monnin, J.; Kuster, F.; Wegener, K. Optimal control for chatter mitigation in milling-Part 1: Modeling and control design. Control Eng. Pract. 2014, 24, 156-166. [CrossRef]

22. Munoa, J.; Beudaert, X.; Erkorkmaz, K.; Iglesias, A.; Barrios, A.; Zatarain, M. Active suppression of structural chatter vibrations using machine drives and accelerometers. CIRP Ann. Manuf. Technol. 2015, 65, 385-388. [CrossRef]

23. Feng, J.; Wan, M.; Dong, Z.Y.; Zhang, W.H. A unified process damping model considering the varying stiffness of the milling system. Int. J. Mach. Tools Manuf. 2019, 147, 103470. [CrossRef]

24. Wan, S.; Li, X.; Su, W.; Yuan, J.; Hong, J.; Jin, X. Active damping of milling chatter vibration via a novel spindle system with an integrated electromagnetic actuator. Precis. Eng. 2019, 57, 203-210. [CrossRef]

25. Moradi, H.; Vossoughi, G.; Behzad, M.; Movahhedy, M.R. Vibration absorber design to suppress regenerative chatter in nonlinear milling process: Application for machining of cantilever plates. Appl. Math. Model. 2015, 39, 600-620. [CrossRef]

26. Wan, S.; Li, X.; Su, W.; Yuan, J.; Hong, J. Active chatter suppression for milling process with sliding mode control and electromagnetic actuator. Mech. Syst. Signal Process. 2020, 136, 106528. [CrossRef]

27. Pu, H.; Yuan, S.; Peng, Y.; Meng, K.; Zhao, J.; Xie, R.; Huang, Y.; Sun, Y.; Yang, Y.; Xie, S.; et al. Multi-layer electromagnetic spring with tunable negative stiffness for semi-active vibration isolation. Mech. Syst. Signal Process. 2019, 121, 942-960. [CrossRef]

28. Wang, F.C.; Lee, C.H.; Zheng, R.Q. Benefits of the inerter in vibration suppression of a milling machine. J. Frankl. Inst. 2019, 356, 7689-7703. [CrossRef] 
29. Díaz-Tena, E.; López de Lacalle, L.N.; Campa, F.J.; Chaires, D.L. Use of Magnetorheological Fluids for Vibration Reduction on the Milling of Thin Floor Parts. Procedia Eng. 2013, 63, 835-842. [CrossRef]

30. Muhammad, B.B.; Wan, M.; Feng, J.; Zhang, W. Dynamic damping of machining vibration: A review. Int. J. Adv. Manuf. Technol. 2017, 89, 2935-2952. [CrossRef]

31. Puma-Araujo, S.D.; Olvera-Trejo, D.; Martínez-Romero, O.; Urbikain, G.; Elías-Zúñiga, A.; López de Lacalle, L.N. Semi-Active Magnetorheological Damper Device for Chatter Mitigation during Milling of Thin-Floor Components. Appl. Sci. 2020, 10, 5313. [CrossRef]

32. Chen, W.; Huo, D.; Shi, Y.; Hale, J.M. State-of-the-art review on vibration-assisted milling: Principle, system design, and application. Int. J. Adv. Manuf. Technol. 2018, 97, 2033-2049. [CrossRef]

33. Albertelli, P.; Braghieri, L.; Torta, M.; Monno, M. Development of a generalized chatter detection methodology for variable speed machining. Mech. Syst. Signal Process. 2019, 123, 26-42. [CrossRef]

34. Yao, Y.-C.; Chen, Y.-H.; Liu, C.-H.; Shih, W.-P. Real-time chatter detection and automatic suppression for intelligent spindles based on wavelet packet energy entropy and local outlier factor algorithm. Int. J. Adv. Manuf. Technol. 2019, 103, 297-309. [CrossRef]

35. Yang, K.; Wang, G.; Dong, Y.; Zhang, Q.; Sang, L. Early chatter identification based on an optimized variational mode decomposition. Mech. Syst. Signal Process. 2019, 115, 238-254. [CrossRef]

36. Caliskan, H.; Kilic, Z.M.; Altintas, Y. On-line energy-based milling chatter detection. J. Manuf. Sci. Eng. 2018, 140, 111012. [CrossRef]

37. Song, Q.; Ju, G.; Liu, Z.; Ai, X. Subdivision of chatter-free regions and optimal cutting parameters based on vibration frequencies for peripheral milling process. Int. J. Mech. Sci. 2014, 83, 172-183. [CrossRef]

38. Urbikain, G.; Olvera, D.; López de Lacalle, L.N.; Elías-Zúñiga, A. Spindle speed variation technique in turning operations: Modeling and real implementation. Sound Vib. 2016, 383, 384-396. [CrossRef]

39. Kaliński, K.J.; Galewski, M. Chatter Vibration Surveillance by the Optimal-linear Spindle Speed Control. Mech. Syst. Signal Process. 2011, 25, 383-399. [CrossRef]

40. Kaliński, K.J.; Galewski, M.A. Optimal Spindle Speed Determination for Vibration Reduction during Ball-End Milling of Flexible Details. Int. J. Mach. Tools Manuf. 2015, 92, 19-30. [CrossRef]

41. Kaliński, K.J. A Surveillance of Dynamic Processes in Mechanical Systems; The Publication of Gdansk University of Technology: Gdansk, Poland, 2012. (In Polish)

42. Kaliński, K.J.; Galewski, M.A.; Mazur, M.R. High Speed Milling vibration surveillance with optimal spindle speed based on optimal speeds map. Key Eng. Mat. 2014, 597, 125-130. [CrossRef]

43. Uriarte, L.; Zatarain, M.; Axinte, D.; Yague-Fabra, J.; Ihlenfeldt, S.; Eguia, J.; Olarra, A. Machine tools for large parts. CIRP Ann. Manuf. Technol. 2013, 62, 731-750. [CrossRef]

44. Totis, G.; Albertelli, P.; Torta, M.; Sortino, M.; Monno, M. Upgraded stability analysis of milling operations by means of advanced modeling of tooling system bending. Int. J. Mach. Tools Manuf. 2017, 113, 19-34. [CrossRef]

45. Kaliński, K.J.; Galewski, M.A.; Mazur, M.R.; Morawska, N. A technique of experiment aided virtual prototyping to obtain the best spindle speed during face milling of large-size structures. Meccanica 2021, 56, 825-840. [CrossRef]

46. Kaliński, K.J.; Galewski, M.A. Vibration surveillance supported by Hardware-In-the-Loop simulation in milling flexible workpieces. Mechatronics 2014, 24, 1071-1082. [CrossRef]

47. Yao, Z.; Mei, D.; Chen, Z. On-line chatter detection and identification based on wavelet and support vector machine. J. Mater. Process. Technol. 2010, 5, 713-719. [CrossRef]

48. Fu, Y.; Zhang, Y.; Zhou, H.; Li, D.; Liu, H.; Qiao, H.; Wang, X. Timely online chatter detection in end milling process. Mech. Syst. Signal Process. 2016, 75, 668-688. [CrossRef]

49. Kuljanic, E.; Totis, G.; Sortino, M. Development of an intelligent multisensor chatter detection system in milling. Mech. Syst. Signal Process. 2009, 23, 1704-1718. [CrossRef]

50. Mazur, M.; Galewski, M.A.; Kaliński, K.J. FPGA based Real Time simulations of the face milling process. IEEE Access 2020, 8 , 215987-216002. [CrossRef]

51. Rodríguez-Andina, J.J.; Valdés-Peña, M.D.; Moure, M.J. Advanced features and industrial applications of FPGAs-A review. IEEE Trans. Ind. Inform. 2015, 11, 853-864. [CrossRef]

52. Fayose, R.S. Development of analogue computer for the simulation of linear circuits and systems. Int. J. Res. Appl. Sci. Eng. Techn. 2015, 3, 97-106.

53. Urbikain, G.; López de Lacalle, L.N. MoniThor: A complete monitoring tool for machining data acquisition based on FPGA programming. SoftwareX 2020, 11, 100387. [CrossRef]

54. Naets, F.; Tamarozzi, T.; Heirman, G.H.K.; Desmet, W. Real-time flexible multibody simulation with global modal parameterization. Multibody Syst. Dyn. 2012, 27, 267-284. [CrossRef]

55. Ehmann, K.F.; Kapoor, S.G.; DeVor, R.E.; Lazoglu, I. Machining process modeling: A review. Trans. ASME J. Manuf. Sci. Eng. 1997, 119, 655-663. [CrossRef]

56. Lee, H.; Cho, D.W.; Ko, T.J.; Yun, W.S.; Ehmann, K.F. Prediction of Cutting Forces in Micro-End-Milling Using the CuttingCondition-Independent Cutting Force Coefficients. Trans. NAMRI/SME 2006, 34, 453-459.

57. Yoon, H.S.; Ehmann, K.F. Dynamics and stability of micro-cutting operations. Int. J. Mech. Sci. 2016, 115-116, 81-92. [CrossRef] 
58. Kpenyigba, K.M.; Jankowiak, T.; Rusinek, A.; Pesci, R. Influence of projectile shape on dynamic behavior of steel sheet subjected to impact and perforation. Thin-Walled Struct. 2013, 65, 93-104. [CrossRef]

59. Faure, L.; Bolle, B.; Philippon, S.; Schuman, C.; Chevrier, P.; Tidu, A. Friction experiments for titanium alloy tribopairs sliding in dry conditions: Sub-surface and surface analysis. Tribol. Int. 2012, 54, 17-25. [CrossRef]

60. Castro, L.R.; Vieville, P.; Lipinski, P. Influence of the coupling between the structural behaviour and the repeated shear bands appearance on the turning quality. Int. J. Mach. Mach. Mater. 2007, 2, 244-253. [CrossRef]

61. Kiran, K.; Kayacan, M.C. Cutting force modeling and accurate measurement in milling of flexible workpieces. Mech. Syst. Signal Process. 2019, 133, 106284. [CrossRef]

62. Eksioglu, C.; Kilic, Z.M.; Altintas, Y. Discrete-Time Prediction of Chatter Stability, Cutting Forces, and Surface Location Errors in Flexible Milling Systems. Trans. ASME J. Manuf. Sci. Eng. 2012, 134, 061006. [CrossRef]

63. Heylen, W.; Lammens, S.; Sas, P. Modal Analysis Theory and Testing; KU Leuven: Leuven, Belgium, 2007.

64. Maia, N.M.M.; Silva, J.M.M. Theoretical and Experimental Modal Analysis; Research Studies Press: Taunton, UK, 1997.

65. Feld, M. Fundamentals of Designing Technological Processes of Typical Machine Parts; The Scientific and Technical Publication: Warsaw, Poland, 2000. (In Polish) 